\title{
In Vitro Analysis of Optimal Stimuli for Phase-Locking and Time-Delayed Modulation of Firing in Avian Nucleus Laminaris Neurons
}

\author{
A. D. Reyes, ${ }^{1,2}$ E. W. Rubel, ${ }^{1}$ and W. J. Spain ${ }^{1,3,4}$ \\ 1 Virginia Merrill Bloedel Hearing Research Center and Divisions of 2 Medical Genetics and ${ }^{3}$ Neurology, Department of \\ Medicine, University of Washington School of Medicine, Seattle, Washington 98195, and 4Seattle VA Medical Center, \\ Seattle, Washington 98108
}

\begin{abstract}
Neurons of the avian nucleus laminaris (NL) provide a neural substrate for azimuthal sound localization. We examined the optimal stimuli for NL neurons to maintain high discharge rates, reliable phase-locking, and sensitivity to time-delayed stimuli. Whole-cell recordings were performed in chick [embryonic days 19-21 (E19-E21)] NL neurons using an in vitro slice preparation. Variation of membrane properties along the tonotopic axis was examined. Computer-controlled intracellular current injection was used to mimic postsynaptic currents or conductances (PSCs) generated in NL neurons by the firing of nucleus magnocellularis (NM) neurons during acoustic stimulation. At various stimulus frequencies, the effects of varying the number of NM cells and PSC amplitudes on firing rate and phase-locking were examined. During high-frequency stimulation, the greatest firing rate and phase-locking occurred when the protocol contained few NM cells that generated large PSCs.
\end{abstract}

Because the stimulus-evoked unitary PSCs are small, we propose that NM cells fire in synchrony to generate large PSCs. To mimic the arrival of PSCs during binaural stimulation, two stimulus trains were summed at different delays before injection. The firing rate of NL neurons was greatest with zero delay. A delay of half the stimulus period evoked firing that was less than that evoked with a single train. Neurons lacking strong outward rectification exhibited neither reliable phase-locking during high-frequency stimulation nor sensitivity to stimulus delays. These findings suggest that the firing responses of NL neurons are determined primarily by their membrane properties.

Key words: nucleus laminaris; nucleus magnocellularis; sound localization; dynamic clamp; phase-locking; outward rectification; coincidence detection
Localization of low-frequency sound along the azimuth is encoded as interaural time delays by the auditory nervous system (Goldberg and Brown, 1969; Moushegian et al., 1975; Crow et al., 1978; Carr and Konishi, 1990; Yin and Chan, 1990; Overholt et al., 1992). In avians, nucleus laminaris (NL) provides the substrate for processing interaural time delays (Parks and Rubel, 1975; Rubel and Parks, 1975; Young and Rubel, 1983; Carr and Konishi, 1990; Overholt et al., 1992). NL contains the third-order neurons that are innervated bilaterally by afferents from nucleus magnocellularis (NM). This organization transforms differences in the arrival times of sound to the ears to delays in the arrival times of impulses to NL neurons (Carr and Konishi, 1990; Overholt et al., 1992; Joseph and Hyson, 1993).

The firing of the NL neurons is modulated by differences in the arrival limes of sound to the ears (Carr and Konishi, 1990). During binaural stimulation, there is an optimal delay that produces the greatest response and a delay during which firing is less than that evoked during monaural stimulation. Interaural time

Received July 6, 1995; revised Oct. 24, 1995; accepted Oct. 26, 1995.

This work was supported by a Department of Veterans Affairs Merit Review, the V. M. Bloedel Hearing Research Center, NIH Grants DCO0395 and DC 02254, and a Blethen Fellowship. We thank Drs. P. Schwindt, E. Fetz, W. Lippe, and R. Powers for valuable comments on this manuscript, and we thank $R$. Lee for technical assistance.

Correspondence should be addressed to Dr. William Spain, Seattle VA Medical Center, Mailstop 127, 1660 South Columbian Way, Scattle, WA 98108.

Dr. Reyes' pusestl address: Max Planck Institut fur Medizinische Forschung, Abteilung Zellphysiologie, D-69012 Heidelberg, Germany.

Copyright (1) 1996 Society for Neuroscience $0270-6474 / 96 / 160993-15 \$ 05.00 / 0$ delays on the order of microseconds can alter the firing rate. This sensitivity is possible in part because NL neurons can phase-lock and maintain high discharge rates even during high-frequency stimulation (Carr and Konishi, 1990). Similar observations were made for neurons in the medial superior olivary (MSO) nucleus, the mammalian analog of NL (Goldberg and Brown, 1969; Moushegian et al., 1975; Crow et al., 1978; Yin and Chan, 1990).

The mechanisms that enable NL neurons to analyze precise temporal information are unclear. Maintenance of phase-locking and high firing rates in cochlear nucleus neurons of birds and mammals is attributable primarily to the postsynaptic membrane properties (Oertel, 1983; Manis and Marx, 1991; Reyes et al., 1994; Rothman et al., 1994; Zhang and Trussell, 1994). One possible mechanism underlying binaural modulation of firing involves inhibitory circuits. Anatomical (Carr et al., 1989; Code et al., 1989; von Bartheld et al., 1989; Lachica et al., 1994) and electrophysiological studies (Yin and Chan, 1990); Groethe and Sanes, 1994) suggest that inhibitory neurons are important for binaural modulation of firing in NL and MSO neurons, respectively. Specifically, inhibition at nonoptimal binaural delays is postulated to cause the firing rate to decrease below that observed during monaural stimulation. However, removal of inhibition does not eliminate modulation (Fujita and Konishi, 1991). Moreover, using a simple neuronal model Colburn et al. (1990) simulated binaural modulation with only excitatory inputs. In this report, we examine the possibility that modulation is caused by the postsynaptic membrane properties of NL neurons and does not involve inhibitory circuitry. 
Using whole-cell recording techniques, we determined the optimal stimuli for maintaining high discharge rates, reliable phaselocking, and modulation of firing during time-delayed stimulation. The primary goals were (1) to examine the extent to which the in vivo firing behavior of NL neurons is determined by their membrane properties, and (2) to gain insight regarding the functional integration of inputs to NL neurons. Under computer control, neurons were stimulated intracellularly with current that resembled synaptic currents arriving in NL during acoustic stimulation. When we used this technique, the contribution of the membrane properties to NL firing was isolated from the possible effects of inhibitory circuits.

\section{MATERIALS AND METHODS}

Slice preparation. Details of the slicing procedure are outlined in Reyes et al. (1994). Briefly, chicks [embryonic days 19-21 (E19-E21)] were decapitated and a $1 \mathrm{~cm}$ section of the skull containing the brainstem was removed with a razor blade and quickly submerged in cooled $\left(4^{\circ} \mathrm{C}\right)$ artificial CSF (ACSF). ACSF contained (in mm): $130 \mathrm{NaCl}, 26 \mathrm{NaH}_{2} \mathrm{CO}_{3}$, $3 \mathrm{KCl}_{2} 2 \mathrm{CaCl}_{2}, 2 \mathrm{MgCl}_{2}, 1.25 \mathrm{NaH}_{2} \mathrm{PO}_{4}$, and 10 dextrose. A $2 \mathrm{~mm}$ transverse section of the brainstem containing NL was dissected and transferred to a Vibratome tissue slicer (TPI, St. Louis, MO). Approximatcly cight $150-200 \mu \mathrm{m}$ coronal slices were made and placed in separate compartments in a holding chamber filled with ACSF, maintained at $34^{\circ} \mathrm{C}$, and gassed with $95 \% \mathrm{O}_{2} / 5 \% \mathrm{CO}$ to maintain $\mathrm{pH}$ at 7.4 .

Whole-cell recordings. Individual slices were transferred to a $0.5 \mathrm{~cm}^{3}$ recording chamber mounted on a standard Zeiss microscope (Thornwood, NY) with fixed stage and perfused with warmed $\operatorname{ACSF}\left(\sim 40^{\circ} \mathrm{C}\right)$ at a rate of $\sim 1.5 \mathrm{ml} / \mathrm{min}$. Individual neurons were viewed with a $40 \times$ water-immersion lens using differential interference contrast optics.

The electrodes were drawn from $75 \mu$ l borosilicate hematocrit tubing (VWR, San Francisco, CA) and were filled with (in mM): 0.1 EGTA, 15 $\mathrm{KCl}, 100 \mathrm{~K}$-gluconatc, $5 \mathrm{MgCl}_{2}, 10 \mathrm{HEPES}, 4 \mathrm{Na}_{2}$-ATP, 10 phosphocreatine, and $0.5-1 \%$ biocytin. $\mathrm{pH}$ was adjusted to 7.2 with $\mathrm{KOH}$. The osmolality was $290 \mathrm{mOsm}$. Voltage traces and plots shown in all figures were corrected for a measured junction potential of $-11 \mathrm{mV}$.

Current-clamp experiments werc performed with an Axoclamp $2 \mathrm{~A}$ (Axon Instruments, Foster City, CA) amplifier in bridge mode. Voltage and current traces were low-pass-filtered at $5 \mathrm{kHz}$ and recorded on videotapes using pulse-code modulation with a frequency response of 44 $\mathrm{kHz}$. Data were digitized off-line and stored on a computer for further analysis.

After the experiments, slices containing recorded neurons were processed for biocytin labeling in whole-mount sections using the procedure described by Horikawa and Armstrong (1988). Other slices from the same animal were stained with cresyl violet. From histological reconstruction of $\mathrm{NL}$, the approximate locations of the recorded neurons along the tonotopic axis were determined from maps provided by Rubel and Parks (1975) and Lippe (1987).

Stimulation of afferents. Synaptic currents or potentials were evoked with bipolar, tungsten electrodes placed cither in the ipsilateral NM or in the arcuate fibers of the crossed dorsal cochlear tract (XDCT) originating from the contralateral NM. Alternatively, glass monopolar electrodes filled with ACSF were used to stimulate afferents adjacent to the dendrites of NL neurons. An upper limit estimate for the unitary synaptic current or potential was obtained by gradually increasing the stimulus intensity until an all-or-none synaptic event occurred (see Fig. 3A). Approximately $10-20$ stimulus events were taken at each intensity at a rate of $<1 \mathrm{~Hz}$.

Simulation of synuptic current arriving during acoustic stimulation. A computer program, written in the $\mathrm{C}$ programming language for a Macintosh Quadra 950, was used to simulate the activities of NM neurons during a $100 \mathrm{mscc}$ acoustic stimulus. The program calculates the net synaptic current that would reach the soma and spike initiation region of NL neurons and injects the current through the electrode. The protocol reproduces two key aspects of NM firing during in vivo acoustic stimulation (Carr and Konishi, 199(); Warchol and Dallos, 1990). First, the simulated NM neurons fire action potentials that are phase-locked to the stimulus and, second, their average firing rate is comparable with that of acoustically driven NM neurons. The program had four parameters that could be varied independently: (1) the frequency $(F)$ of the acoustic stimulus, (2) the number of NM neurons synapsing onto an NL neuron,
(3) the shape and size of the unitary synaptic currents produced by each NM neuron, and (4) the average firing rate (AFR) of each NM neuron.

Figure 1 illustrates the steps in calculating the injected current. A sinusoid was used to represent a tone stimulus (Fig. $1 B$ ). The frequency of the sinusoid, termed here the stimulus frequency, was varied from 400 to $6000 \mathrm{~Hz}$. A train of impulses then was calculated for each NM neuron (Fig. 1C). In this example, three NM cells project onto an NL cell. The impulses were phase-locked to the tone, that is, they occurred at a fixed phase of the sinusoid, although not necessarily on every cycle. The intervals between impulses were multiples of the acoustic stimulus period $(=1 / F)$ and were randomly determined as follows. The probability of an impulse occurring at a particular cycle was defined as AFR/F. At successive stimulus cycles, a uniformly distributed random number, ranging from 0 to 1, was drawn; an impulse occurred if the number was $\leq \mathrm{AFR} / F$. The impulses then were summed in a histogram $[H(t)$; Fig. $1 D]$.

An important feature of this algorithm was that AFR and $F$ could be varied independently. In vivo recordings reveal that the AFR of NM neurons does not vary systematically with their best frequencies (Carr and Konishi, 1990; Warchol and Dallos, 1990). Therefore, AFR was fixed at $250 \mathrm{~Hz}$ (unless specified otherwise) and did not vary with the stimulus frequency. $\Lambda$ s the stimulus frequency increased, the simulated NM impulses remained phase-locked but skipped more cycles to maintain a constant AFR.

In some experiments, the distribution of interspike intervals (ISIs) was Poisson. ISIs were determined as follows. A random integer. $R$, was drawn from the Poisson distribution with mean F/AFR. The duration of the ISI after an NM spike was given by $R / F$. The mean interval, therefore, was $1 /$ AFR. This technique was valid only when $F$ was considerably greater than AFR: when F/AFR was low, $R$ was often zero, so the calculated ISI was zero. The result was that two spikes occurred at the same time. The protocol could be modified to ignore zeros, but then $F$ and AFR could not he varied independently. In this report, this algorithm was used only when $F / A F R \geq 4$. form:

Each NM impulse generates a unitary current, $I_{\mathrm{u}}(t)$, in NL with the

$$
I_{\mathrm{u}}(t)=k \alpha t \cdot \exp (1-\alpha t),
$$

where $k$ is the amplitude, $\alpha$ determines the shape, and $t$ is time (Fig. $1 A$ ). $I_{\mathrm{u}}(t)$ was calculated in time increments of 20 or $25 \mu \mathrm{sec} . l_{\mathrm{u}}(t)$ was then injected, via a digital-to-analog (D/A) converter (GW Instruments, Somerville, MA) and the Axoclamp amplifier, into the recorded cell. The parameters $k$ and $\alpha$ were adjusted so that the resulting voltage deflections resembled stimulus-evoked synaptic potentials (see Fig. $3 B$ ). D/A conversion occurred at a rate of either 40 or $50 \mathrm{kHz}$.

The net postsynaptic current (PSC; $I_{\mathrm{n}}(t)$, Fig. $1 E$ ) generated by the NM cells was calculated from the following convolution integral:

$$
I_{\mathrm{n}}(t)=\int H(t-\tau)^{*} I_{\mathrm{u}}(\tau) \mathrm{d} \tau .
$$

$I_{\mathrm{n}}(t)$ then was injected into the cell.

Alternatively, the computer was used to mimic the change in conductance produced by synaptic events. The technique used, termed here conductance clamp, is very similar to that described by Sharp et at. (1993a,b) and by Robinson and Kawai (1993). Synaptic current, $I_{\mathrm{s}}(V, t)$, can be represented as:

$$
I_{s}(V, t)=g_{s}(t) *\left(V-V_{s}\right),
$$

where $g_{s}(t)$ is the synaptic conductance that takes the form of an $\alpha$ function (Eq. 1), $V$ is the membrane potential, and $V_{\mathrm{s}}$ is the reversal potential for $I_{\mathrm{s}}$. For this study, $V_{\mathrm{s}}$ was set to $0 \mathrm{mV}$, the reversal potential for AMPA receptor-mediated synaptic currents. The excitatory input to NL neurons does not have a significant NMDA component (Zhou and Parks, 1991). The computer alternately performs a rapid analog-to-digital and D/A conversion: within a $25 \mu$ sec period, the computer samples $V$, calculates Equation 3, and then injects $I$, into the cell. The process then is repeated for the entire $100 \mathrm{mscc}$ stimulus train. Thus, the injected current varies dynamically with the membrane potential. Figure $1 F$ shows an example of a conductance change specified by the computer (lowest trace), the resulting current that was injected into the neuron at resting potential ( $-60 \mathrm{mV}$; second trace from bottom), and the voltage deflections at various holding potentials (top five traces). The deflections reversed at $0 \mathrm{mV}$. For a train of impulses, the net synaptic conductance, $g_{n}(t)$, was calculated using Equation 2, where $g_{n}(t)$ is substituted for $I_{n 1}(t)$ and $g_{\mathrm{s}}(\tau)$ 
A Unitary

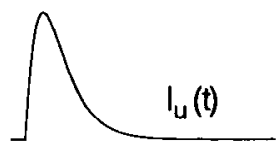

B ${ }_{\substack{\text { Impulse } \\ \text { Trains }}}^{\text {Tone }}$

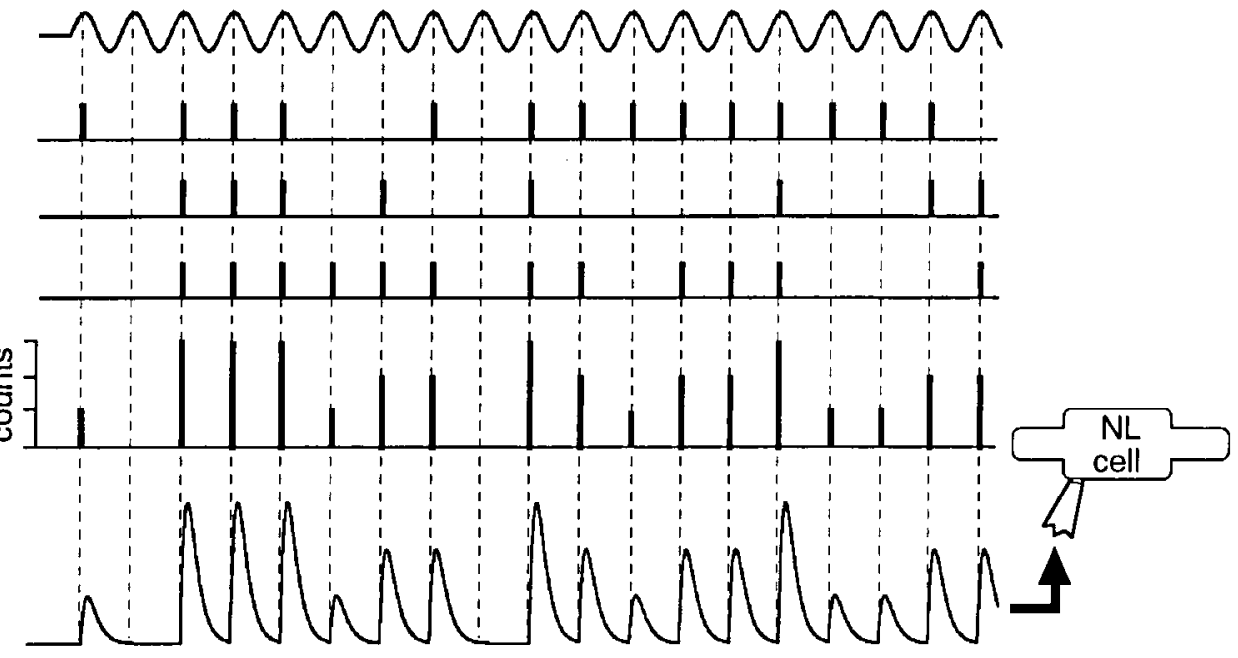

$\mathrm{F}$

Membrane Potential

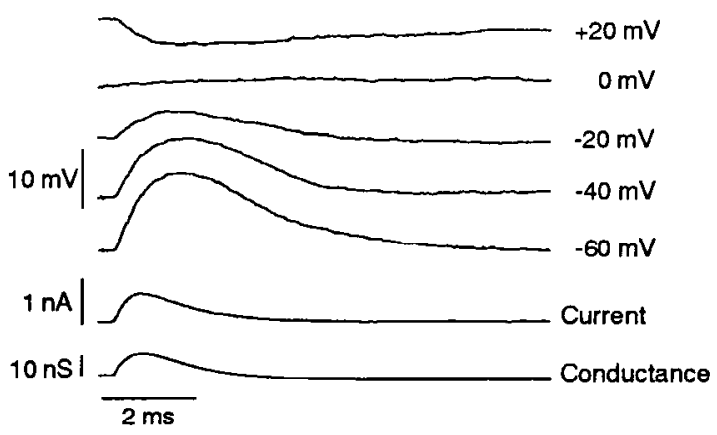

G

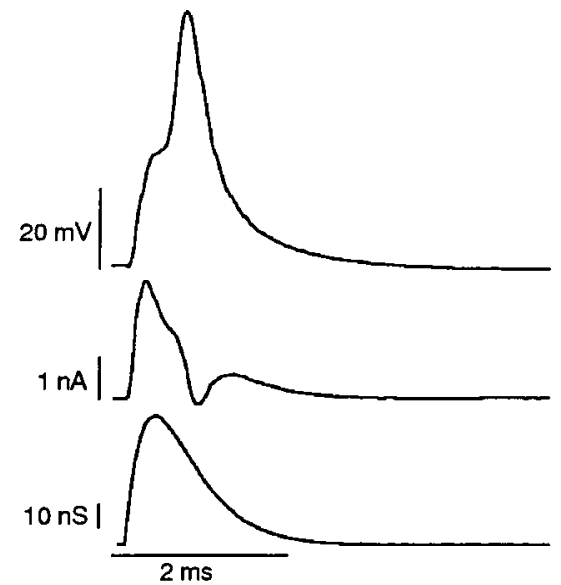

Figure 1. Computer-controlled injection of current. $A$, Computer-generated synaptic current, $I_{\mathrm{u}}(t)$, calculated with Equation 1 (see Materials and Methods). $B$, Sinusoid representing tone stimulus. $C$, Simulated impulse trains generated for three magnocellularis neurons. Each impulse was phase-locked to the sinusoid. $D$, Impulse trains were accumulated in a histogram $[H(t)] . E$, Composite current was calculated by convolving $H(t)$ with $I_{\mathrm{u}}(t)$. The resulting waveform was injected into the recorded cell via a $\mathrm{D} / \mathrm{A}$ converter and the recording amplifier. $F$, Conductance changes produced in an NL neuron by an NM impulse were replicated using a computer (lowest trace). The current injected into the cell at resting potential is shown in the second trace from bottom. The resulting voltage deflections at rest and at successively depolarized holding potentials are shown in the top five traces. $G$, Suprathreshold stimulation (lower trace) under conductance clamp causes an action potential (top trace) and an associated dip in the current trace (middle trace).

is substituted for $I_{u}(\tau)$. The injected current at each time step then was calculated using Equation 3, in which $g_{\mathrm{n}}(t)$ was substituted for $g_{\mathrm{s}}(t)$

Previous studies (Robinson and Kawai, 1993; Sharp et al., 1993a,b) demonstrated that the computer-generated conductance accurately replicates the conductance change produced by a synaptic input. The sampling rate $(40 \mathrm{kHz})$ used in the present experiments was more than twofold higher than the ratc $(17 \mathrm{kHz})$ used by Robinson and Kawai (1993) and eightfold higher than the rate $(5 \mathrm{kHz})$ used by Sharp et al. (1993a,b). Figure $1 G$ shows that a suprathreshold stimulus causes a dip in the current trace caused by a decrease in the driving force caused by the action potential.

The synaptic current reaching the soma and spike initiation region of NL neurons during binaural stimulation was simulated by constructing and summing two sets of trains, representing inputs from the ipsilateral and contratateral NM. A stimulus arriving at different times to each ear was simulated by delaying the onset of one set of trains before summation.
Stimuli were applied 5-50 times at a rate of $0.3 \mathrm{~Hz}$. A different waveform was calculated for each trial. Voltage and current traces were digitized off-line, and various customized programs were used to detect the times of occurrences of action potentials. The average evoked firing rate during each trial was calculated by dividing the number of action potentials by the duration of the stimulus train. Vector strengths were calculated using a procedure similar to that described by Goldberg and Brown (1969). Briefly, the evoked action potentials were placed in period histograms aligned with the sinusoid. The $i$ th bin $\left(w_{i}, 20 \mu \mathrm{sec}\right.$ width) in the histogram was converted to vector angle $(\varnothing)$ by:

$$
\varnothing_{i}=360 * w_{i} / T
$$

where $T$ is the period of the sinusoid. The number of action potentials in a particular bin represents the length of the vector. The vector strength was obtained by summing all the bins vectorially. Thus, a vector strength 

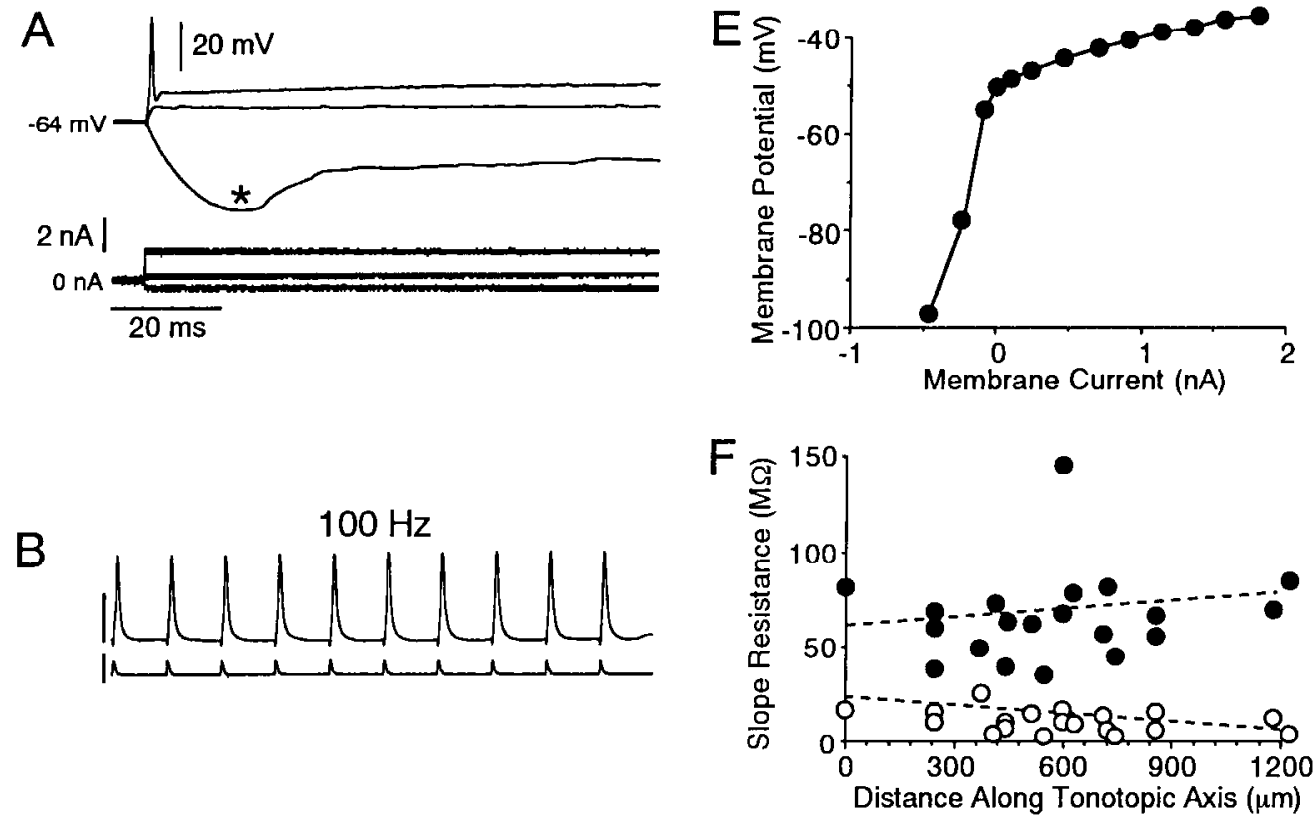

Figure 2. Sub- and suprathreshold properties of NL neurons. $A$, Superimposed voltage responses (top traces) during application of sub- and suprathreshold current steps (bontom traces). $B-D$. Response of the same neuron to repetitive stimulation with transient currents at stimulus rates of 100,500 , and $1000 \mathrm{~Hz}$. Shape of transients was determined by an $\alpha$ function $(\alpha=3$ in Eq. 1). E, Voltage-current relation obtained in another cell. Voltage measurements were made before the sag (asterisk in $A$ ). F, Variation of slope resistance measured below (solid circles) and above (open circles) resting potential. Dotted lines represent the best linear fits. $G$, Variation of timesto-peak of depolarizing voltage responses that peaked at approximately -45 to $-40 \mathrm{mV}$. Data were fitted with a $\log$ function (solid curve). Inset shows schematic of NL and the orientation of tonotopic axis.
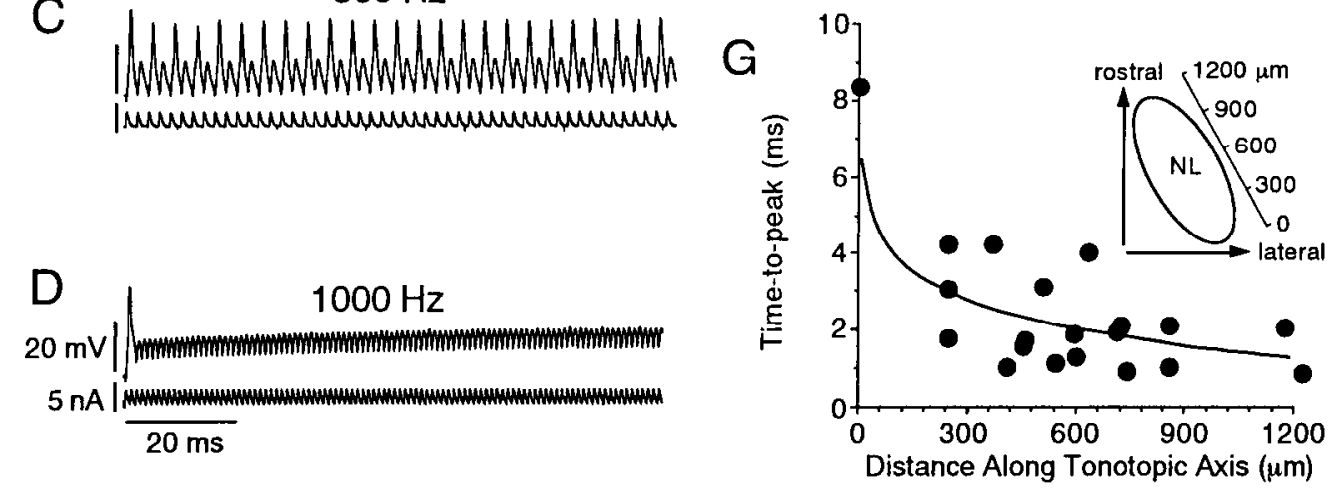

of 1 indicates perfect phase-locking, whereas a value of 0 indicates that the action potentials occurred randomly throughout the interval.

All reported values are given as mean \pm SD unless otherwise specified.

\section{RESULTS}

Whole-cell recordings were performed in 99 NL neurons. Neurons were accepted for analysis if seal resistance between the electrode and the cell membrane before entering the whole-cell configuration mode was $>1 \mathrm{G} \Omega$. The resting potential, measured in 78 cells, was $-59 \pm 5 \mathrm{mV}$. Action potentials were evoked in 37 cells. The remaining cells did not fire action potentials, although their resting potentials were identical $(-59 \pm 5 \mathrm{mV})$ and their input resistances (see below) were very similar to those of cells that did fire action potentials.

Neurons were identified as belonging to NL primarily by their location in the slice. In a transverse slice, NL consists of a single layer of cells in the dorsomedial part of the brainstem. To confirm that the recorded cells were from NL and to determine their location along the tonotopic axis (see Materials and Methods), the cells were routinely labeled with biocytin. Consistent with morphologically identified NL neurons (Smith and Rubel, 1979; Smith, 1981), the recorded neurons had segregated tufts of dendrites that extended dorsally and ventrally (see cells $I I$ and $I I I$ in Fig. 9). Unless specified otherwise, the neurons described in this report are from the rostral three-fourths of NL. In this section of
$\mathrm{NL}$, neurons have characteristic frequencies (CFs) ranging from $\sim 800$ to $\sim 3000 \mathrm{~Hz}$ (Lippe, 1987).

\section{Subthreshold and suprathreshold response properties}

NL neurons exhibited strong outward rectification: the voltage response to a depolarizing current step was substantially smaller than to an equivalent hyperpolarizing step (Fig. $2 A$ ). Hyperpolarizing current steps caused the membrane potential to decay to a minimum and subsequently sag to a less hyperpolarized level. Depolarizing current steps caused the membrane potential to rise and break abruptly to a steady level; larger steps caused a brief peak after which the membrane potential decayed to a lower potential (see Fig. 9B, cell $I I$ ). The effective membrane time constant was considerably less in the depolarizing direction: the depolarizing response peaked within $2 \mathrm{msec}$, whereas the hyperpolarizing response reached its minimum $\sim 20 \mathrm{msec}$ after the step onset.

A plot of voltage response (measured just before the sag; asterisk in Fig. $2 A$ ) versus current ( $V / I$ plot) shows that the rectification started near resting potential (Fig. $2 E$ ). The input resistance, measured from the slope of the relation at potentials below resting potential was $72 \pm 34 \mathrm{M} \Omega(n=31)$. The slope resistance measured at potentials above resting potential was $11 \pm$ $8 \mathrm{M} \Omega(n=31)$. In an additional 13 neurons that did not fire action potentials, the slope resistance measured below resting potential 
was $67 \pm 20 \mathrm{M} \Omega$ and that above resting potential was $14 \pm 6 \mathrm{M} \Omega$. These values were not statistically different from those of neurons that fired action potentials. The pooled values were $71 \pm 30 \mathrm{M} \Omega$ $(n=44)$ for resistance measured below and $12 \pm 7 \mathrm{M} \Omega$ for resistance measured above resting potential.

Figure 2, $F$ and $G$, shows the variation of subthreshold properties along the tonotopic axis. Data were from neurons labeled with biocytin. Figure $2 G$ (inset) shows the orientation of the tonotopic axis in NL; neurons with high CFs are in the rostromedial part of NL (Lippe and Rubel, 1985; I ippe, 1987). Neither the slope resistance measured below (solid circles in $F$ ) or above (open circles in $F$ ) resting potential varied systematically along the tonotopic axis. The slopes of the regression line for resistance above and below resting potential were $1.0 \times 10^{-3} \mathrm{M} \Omega / \mu \mathrm{m}\left(r^{2}=0.02\right.$, $p=0.57 ; n=22)$ and $-6.9 \times 10^{-3} \mathrm{M} \Omega\left(r^{2}=0.13, p=0.12 ; n=\right.$ 22 ), respectively. Figure $2 G$ plots the the time-to-peak of voltage responses to depolarizing current steps against distance along the tonotopic axis. The peaks of the voltage responses ranged from -45 to $-40 \mathrm{mV}$. A statistically significant correlation was obtained when the data were fitted with a log function [time-to-peak $=-2.5 \log ($ distance $\left.), r^{2}=0.68 ; p<0.05\right]$. However, the relation was not significant [time-to-peak $=-2.0 \log ($ distance $) ; p=0.08$, $\left.r^{2}=0.15\right]$ when the data point from the extreme caudal end of the tonotopic axis was excluded from the fit. This indicated that, at least for neurons in the rostral three-fourths of NL, the rise times did not vary significantly along the tonotopic axis.

There was a statistically significant decrease in resting potential of neurons in the caudolateral to rostromedial direction of the tonotopic axis (slope $=-0.01 \mathrm{mV} / \mu \mathrm{m}, p=0.002 ; n=42$ ). However, distance accounted for only $21 \%\left(r^{2}=0.21\right)$ of the variation (data not shown).

In response to a suprathreshold current step, NL neurons fired a single action potential (Fig. $2 A$ ), after which the membrane potential remained below firing threshold. A small, brief afterhyperpolarization followed the action potentials. Firing threshold was at $-42 \pm 6 \mathrm{mV}(n=37)$ or $18 \pm 7 \mathrm{mV}$ above rest. The action potentials peaked at $-15 \pm 17 \mathrm{mV}(n=37)$, and the amplitude, measured from resting potential, was $45 \pm 17 \mathrm{mV}$. The duration of the action potential, measured as the width at half the action potential height, was $0.37 \pm 0.15 \mathrm{mscc}(n=37)$. Nonc of these parameters varied significantly along the tonotopic axis (data not shown).

Repetitive injection of brief, suprathreshold transient currents (Fig. $2 B-D$, bottom traces) evoked repetitive discharge (top traces). At low stimulus frequencies (100 Hz; Fig. $2 B$ ), an action potential was evoked at each cycle. At higher stimulus frequencies ( $500 \mathrm{~Hz}$; Fig. $2 C$ ), the action potentials did not occur on every cycle. At very high stimulus frequencies $(1000$ $\mathrm{Hz}$; Fig. $2 D$ ), only a single action potential was evoked at the start of the train. At these high stimulus frequencies, the individual PSCs summated temporally so that the net injected current was predominantly steady.

\section{Stimulus-evoked synaptic currents}

A goal of this study was to examine the responses of NL neurons to stimuli that closely resemble acoustic stimuli. To replicate PSCs and postsynaptic potentials (PSPs) accurately, it was necessary to obtain reasonable estimates of the shape and size of the unitary PSCs and PSPs. To this end, PSCs and PSPs were evoked in NL by placing stimulating electrodes in the ipsilateral NM, the arcuate fibers originating from contralateral NM, or the white matter immediately adjacent to the dendrites of the recorded neuron.
Figure $3 A$ shows superimposed, successive records of synaptic current evoked under voltage clamp as the stimulus intensity was increased gradually. Low-intensity stimulation evoked no responses; as the intensity was increased gradually, an all-or-none current was evoked that varied little from trial to trial. Although this procedure may not necessarily stimulate a single NM fiber, it nevertheless gives an upper-limit estimate of the unitary PSC amplitude. The amplitude and width (measured at half the PSC amplitude) of the evoked synaptic current were measured at holding potentials near rest.

The evoked unitary PSCs and PSPs were replicated by injecting current through the recording electrode (see Materials and Methods). The time course of the injected current (see Eq. 1) was adjusted so that the resulting voltage deflection resembled the stimulus-evoked PSP. Figure $3 B$ compares the stimulus-evoked PSP and the voltage deflection obtained with injection of the current. The stimulus-evoked PSC recorded under voltage clamp (polarity reversed) also is shown for comparison. In general, stimulus-evoked and computer-generated PSCs that were comparable in shape and size produced comparable PSPs and voltage deflections.

I'o mimic synaptic currents more realistically, the computergenerated PSCs also were injected under conductance clamp. As with AMPA receptor-mediated synaptic currents, the amplitude of the injected current was proportional to the membrane potential and reversed at $0 \mathrm{mV}$ (see Materials and Methods; Fig. $1 F, G$ ). This paradigm may be more appropriate in electrotonically short neurons in which synaptic conductances can affect somatic membrane potential.

Neither the PSC amplitude nor the half-width was correlated strongly with the location of the neurons along the tonotopic axis. Figure $3 C$ plots the PSC amplitude against the location of neurons in the tonotopic axis. Connected symbols show data obtained in individual animals. The slope of the regression line for pooled data was $5.9 \times 10^{-5} \mathrm{n} \mathrm{A} / \mu \mathrm{m}$ and was not significant $\left(p>0.05, r^{2}\right.$ $=0.01$ ). The mean PSC amplitude measured in both labeled and unlabeled cells was $0.23 \pm 0.18 \mathrm{nA}$ (range, $0.05-0.60 \mathrm{mV} ; n=$ 38). A similar plot for PSC half-width is shown in Figure $3 D$. A linear relation (slope, $-7.8 \times 10^{-4}$ ) best described the data; although the relation was statistically significant $(p=0.03)$, the distance along the tonotopic axis accounted for only $18 \%\left(r^{2}=\right.$ 0.179 ) of the variation. The relation was not significant (slope $=$ $1 \times 10^{-5} ; p=0.97, r^{2}=0.00$ ) when the fit was restricted to data in the rostral three-fourths of NL, where most of the recorded neurons were located. The mean half-width of PSCs measured in both labeled and unlabeled cells was $0.76 \pm 0.50 \mathrm{msec}(n=38)$.

\section{Optimal stimulus for firing}

To examine the firing responses of NL neurons, a computer program was used to calculate the current that would be generated in an NL neuron during acoustic stimulation (see Materials and Methods). The protocol reproduces two key aspects of NM firing during in vivo acoustic stimulation (Carr and Konishi, 1990; Warchol and Dallos, 1990). First, the simulated NM neurons fire action potentials that are phase-locked to the stimulus and, second, their AFR is comparable with that of acoustically driven NM neurons. The injected current represents a composite of unitary PSCs generated by a specified number of simulated NM neurons (Fig. 1). The activities of the simulated NM neurons and, therefore, the arrival of PSCs in NL were phase-locked to a sinusoid (Fig. $1 B$ ) that represents a tone stimulus. The frequency of the sinusoid, termed here stimulus frequency, can be varied system- 

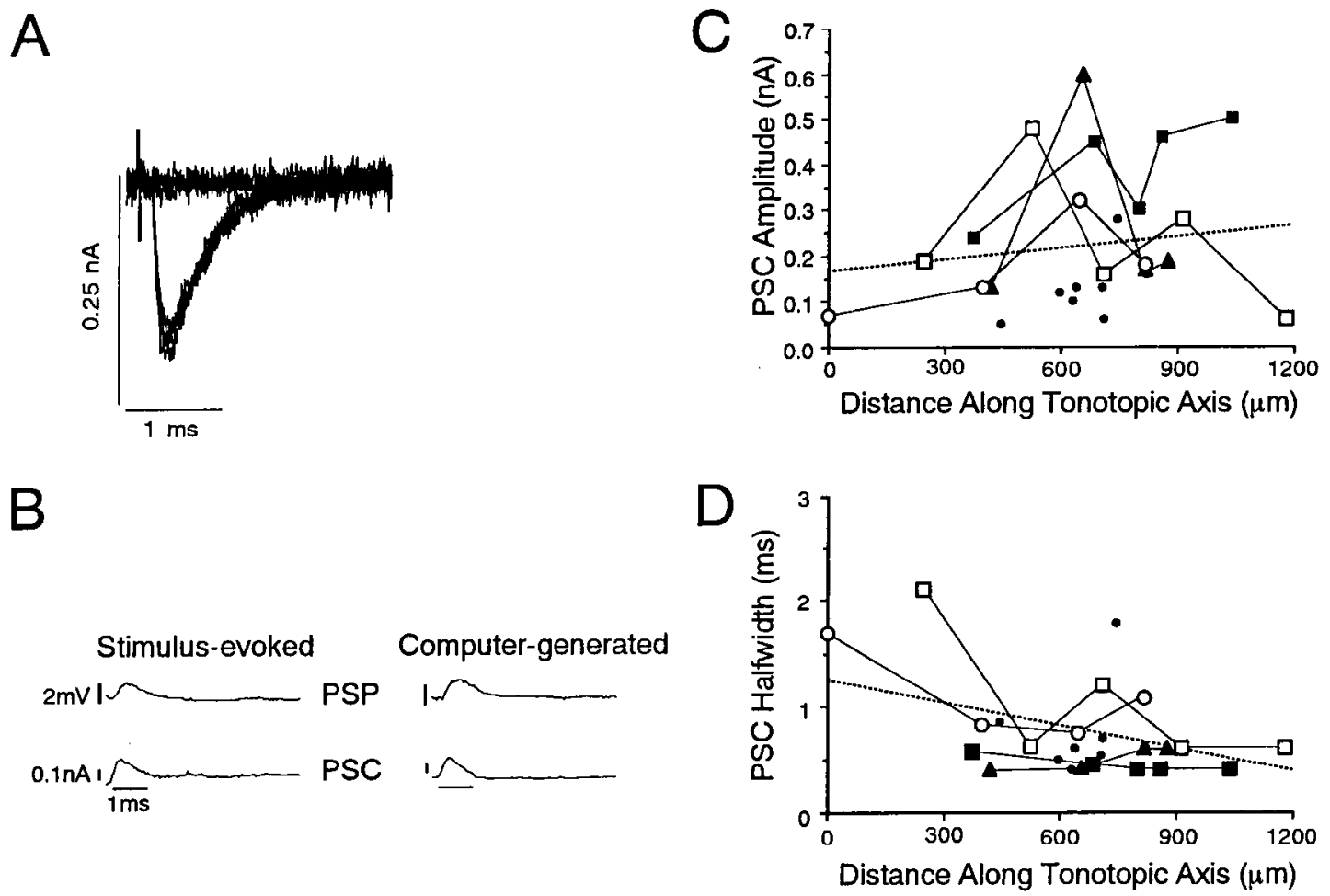

Figure 3. Stimulus- and computer-evoked synaptic currents. $A$, Superimposed voltage-clamp records of synaptic current evoked in an NL neuron by successive stimulation of NM afferents. Stimulation intensity was increased gradually until an all-or-none inward current was evoked. $B$, Comparison of stimulus-evoked and computer-generated PSCs and PSPs in the same cell. Stimulus-evoked PSC is shown with the polarity reversed. Computer-generated PSCs were produced with an $\alpha$ function (see Materials and Methods) and injected as current into the cell. $C, D$, Plot of stimulus-evoked synaptic current amplitude $(C)$ and half-width $(D)$ versus location of neurons along the tonotopic axis. Connected symbols show data obtained from the same chicks. Small solid circles were data from additional chicks. Pooled data were fitted using linear regression (dotted lines).

atically. The composite current (Fig. $1 E$ ) subsequently was injected into the cell through the recording electrode.

The initial goal was to determine how the firing rate evoked in NL neurons varies with the stimulus frequency. The results are summarized in Figure 4. The parameters of the stimulus protocol (see Materials and Methods) were set as follows. The AFR of each simulated $\mathrm{NM}$ cell was $250 \mathrm{~Hz}$, which is in the middle range of firing rate evoked in NM neurons during in vivo acoustic stimulation (Warchol and Dallos, 1990). It is important to note that, as observed in vivo (Carr and Konishi, 1990; Warchol and Dallos, 1990), the AFR of each simulated NM cell was constant regardless of the stimulus frequency (see Materials and Methods). With increasing stimulus frequencies, the simulated NM impulses remained phase-locked but skipped progressively more cycles so that the AFR was maintained at $250 \mathrm{~Hz}$. Hence, the total number of PSCs during a train was also constant. The amplitude of the computer-generated PSCs (see insets in Fig. 4A1,Bl) was $0.2 \mathrm{n} \mathrm{A}$; this is comparable with the mean amplitude of the stimulusevoked PSCs. The number of NM neurons that projects onto a single NL neuron is not documented well for chicks and, therefore, was varied for each stimulus frequency. Stimulation was under current clamp in Figure $4 A$ and under conductance clamp in Figure $4 B$.

A requisite number of simulated $\mathrm{NM}$ neurons was needed to evoke firing in NL neurons. This minimal number increased with increasing stimulus frequencies. Figure $4 A I$ plots the average evoked firing rate against the number of NM neurons for five stimulus frequencies. The first point of each curve gives the number of simulated NM cells in the protocol that evoked at least one action potential. During $500 \mathrm{~Hz}$ stimulation $\sim 10 \mathrm{NM}$ cells were needed to evoke minimal firing, whereas during $1000 \mathrm{~Hz}$ stimulation 20 cells were needed. This occurred partly because the mean amplitude of the injected current at each cycle decreased with increasing stimulus frequency. The mean current per cycle, $I_{\mathrm{c}}$, is given by:

$$
I_{\mathrm{c}}=k \times N \times \mathrm{AFR} / F \text {, }
$$

where $k$ is the amplitude of the unitary PSCs $(0.2 \mathrm{nA}), N$ is the number of NM cells, AFR is the AFR of each NM cell $(250 \mathrm{~Hz})$, and $F$ is the stimulus frequency. The ratio $\mathrm{AFR} / F$ gives the probability of an NM impulse occurring at a given stimulus cycle (see Materials and Methods). During $500 \mathrm{~Hz}$ stimulation with 10 $\mathrm{NM}$ cells, $I_{\mathrm{c}}$ was $1 \mathrm{n} \mathrm{A}$; an equivalent $I_{\mathrm{c}}$ during $1000 \mathrm{~Hz}$ stimulation required $20 \mathrm{NM}$ cells. Equation 5 actually may underestimate $I_{\mathrm{c}}$, particularly during high-frequency stimulation, because temporal summation of the PSCs would increase the current amplitude in successive cycles.

The average evoked firing rate in NL neurons increased with the number of simulated NM cells. At all stimulus frequencies, the evoked firing rates initially rose steeply with the number of NM cells but then became asymptotic to a maximum level. Data points extending past the asymptotic region of the curves were not analyzed because large voltage fluctuations often obscured action potentials. However, the evoked firing rate is not likely to increase substantially with further increases in NM cell number because the sodium conductance started to inactivate (see below).

The evoked firing rate decreased with increasing stimulus fre- 


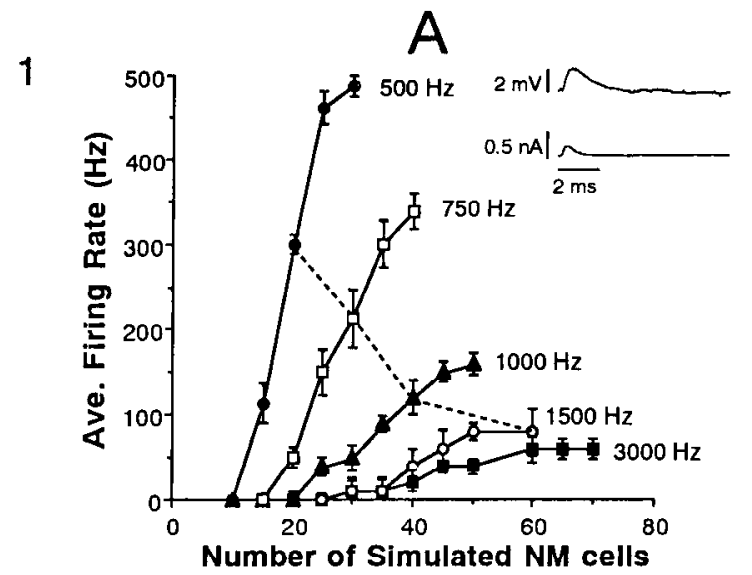

$500 \mathrm{~Hz}, 25$ cells
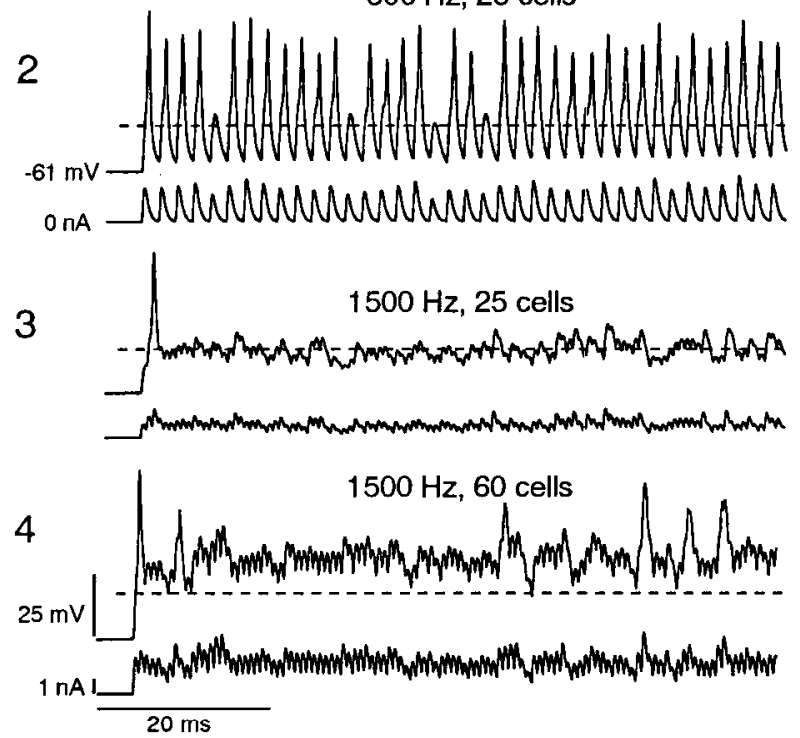

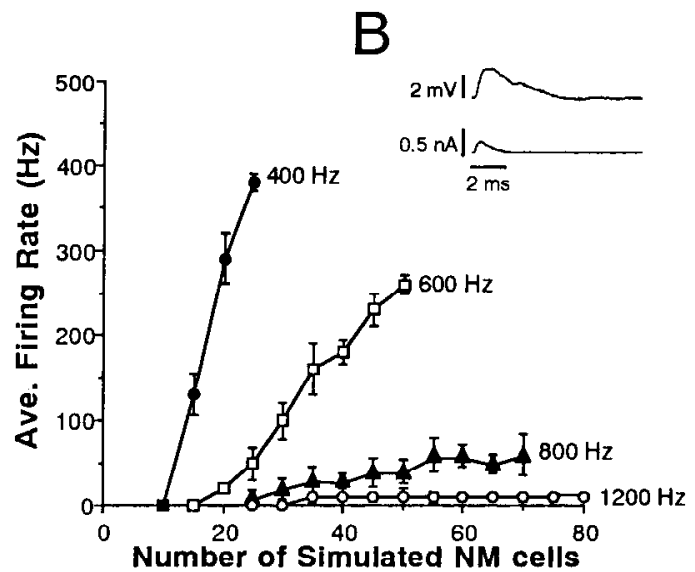

$400 \mathrm{~Hz}, 25$ cells
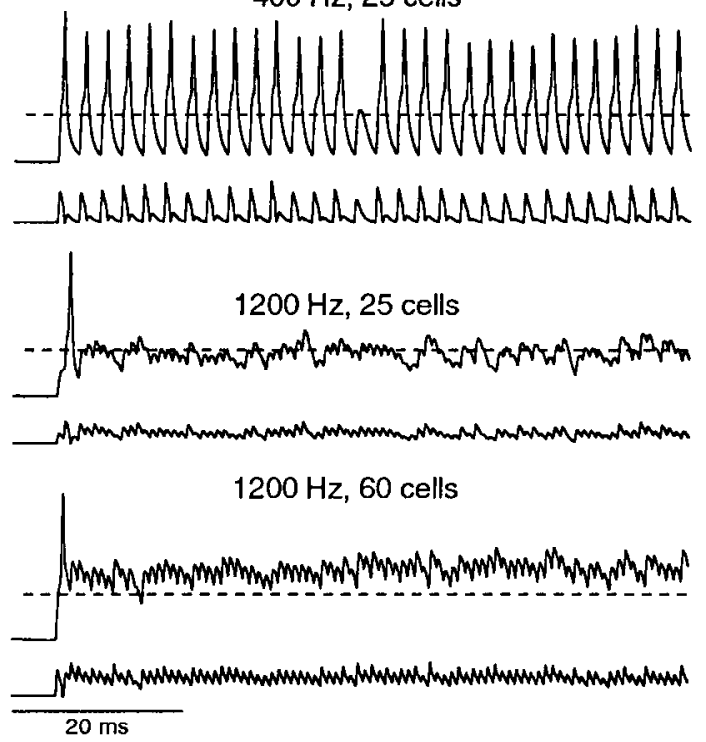

Figure 4. Variation of evoked firing rate with number of simulated NM cells. Al, Plot of average $( \pm$ SD) firing rate of NL neurons versus number of NM cells for a range of stimulus frequencies. Measurements were from five stimulus trains applied under current clamp. The amplitude of the computergenerated PSCs (inset) was $0.2 \mathrm{n}$ A. Dotted line connects data points in which the mean current amplitude at each stimulus cycle was equal. $A 2-A 4$, Voltage (top traces) and current (bottom traces) waveforms during stimulation at $500 \mathrm{~Hz}$ with $25 \mathrm{NM}$ cells $(A 2)$, at $1500 \mathrm{~Hz}$ with $25 \mathrm{NM}$ cells $(A 3)$, and at 1500 $\mathrm{Hz}$ with $60 \mathrm{NM}$ cells $(A 4)$. Dashed line marks voltage threshold for action potentials evoked with a brief, suprathreshold current pulse. $B$, Same as $A$ except stimuli were applied under conductance clamp. $B 2-B 4$, Voltage and current traces during stimulation at $400 \mathrm{~Hz}$ with $25 \mathrm{NM}$ cells $(B 2)$, at $1200 \mathrm{~Hz}$ with $25 \mathrm{NM}$ cells $(B 3)$, and at $1200 \mathrm{~Hz}$ with $60 \mathrm{NM}$ cells $(B 4)$.

quency. During low-frequency stimulation (e.g., $500 \mathrm{~Hz}$ ), NL firing rate rose steeply with the number of NM cells to a relatively high level. As the stimulus frequency increased, the slope of the relation shallowed and the maximum evoked firing rate decreased. For example, during $500 \mathrm{~Hz}$ stimulation the evoked firing rate plateaued near $500 \mathrm{~Hz}$, whereas during $3000 \mathrm{~Hz}$ stimulation the firing rate plateaued at $50 \mathrm{~Hz}$. The decrease in the evoked firing rate still occurred, although the mean current per cycle, as calculated by Equation 5, was constant. In Figure $4 A 1$ the dotted line connects points in which the mean current per cycle was equal.

The time course of the injected current became progressively more steady as the stimulus frequency increased. During $500 \mathrm{~Hz}$ stimulation with 25 simulated NM cells, the composite current (Fig. 4A2, bottom trace) had distinct peaks that occurred regularly at a rate equal to the stimulus frequency. The neuron fired action potentials on nearly every cycle. During stimulation at $1500 \mathrm{~Hz}$ with $25 \mathrm{NM}$ cells (Fig. 4A3), the injected current was predomi- nantly steady; this occurred because the PSCs were distributed over many cycles and hence summated temporally. As with steady current injection, only a single action potential was initiated at the start of the train. In contrast, during low-frequency stimulation, the same number of PSCs was distributed over fewer cycles that were well separated in time; consequently, less temporal summation occurred.

The decrease in the number of action potentials during high-frequency stimulation occurred partly because the voltage threshold increased. In Figure $4 A 3$, several of the voltage deflections exceeded threshold (for action potentials evoked with a single suprathreshold stimulus; dotted lines) but failed to evoke action potentials. The neurons were still capable of firing; a further increase in the number of NM cells did evoke additional action potentials (Fig. 4A4). However, the action potentials were shorter and broader than those evoked at the start of the train, indicating that the sodium conductance inactivated partially. 

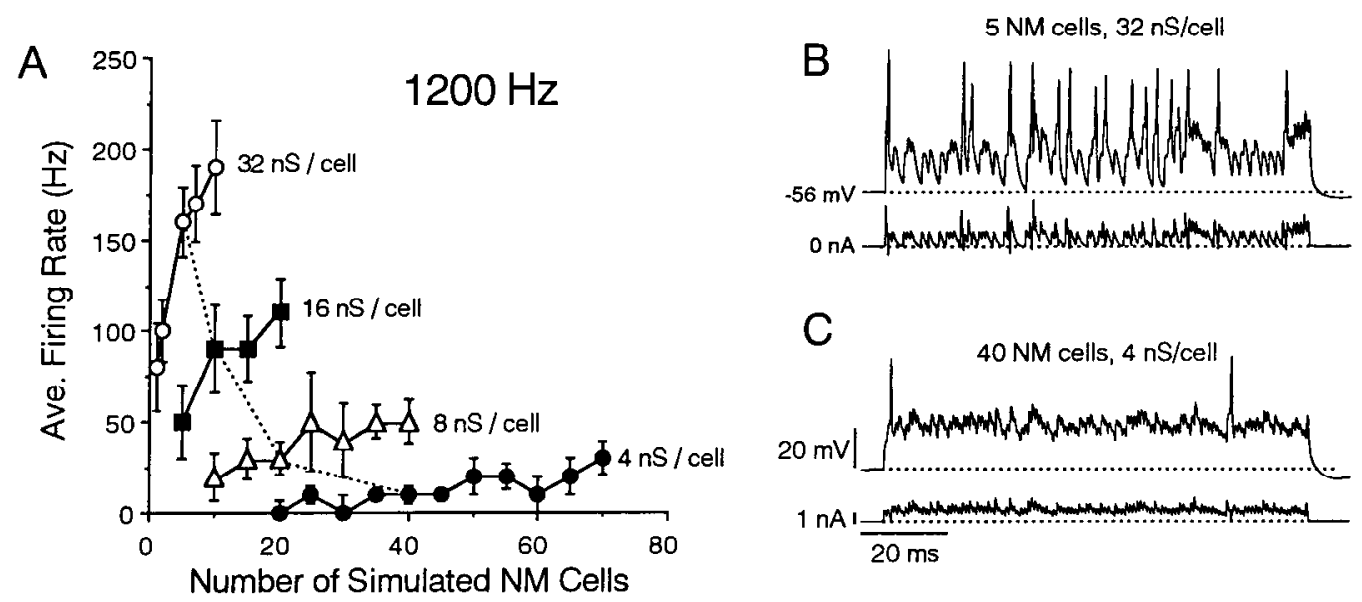

Figure 5. Variation of evoked firing rate with PSC amplitude. $A$, Plot of average ( \pm SD) firing rate versus number of NM cells for a range of PSC amplitudes. Measurements were from five stimulus trains applied under conductance clamp. Stimulus frequency was $1200 \mathrm{~Hz}$. Numbers give amplitude of unitary conductance used for each curve. Dotted line connects points in which the amplitude of the total conductance change (number of NM cells $\times$ amplitude of unitary synaptic conductance) was comparable. $B$, Voltage (top trace) and current (bottom trace) records obtained during stimulation with five NM cells. Each NM impulse produced a conductance change of $32 \mathrm{nS}$. $C$, Similar waveforms obtained during stimulation with $40 \mathrm{NM}$ cells. Each NM impulse produced a conductance change of $4 \mathrm{nS}$.

Similar observations were made under conductance clamp in the same cell (Fig. $4 B$ ). The amplitude of the computer-generated conductance was $4 \mathrm{nS}$, which produced a $\sim 0.2 \mathrm{nA}$ PSC when applied at rest. As was observed under current clamp, the maximum evoked firing under conductance clamp was greatest during low-frequency stimulation and decreased with increasing stimulus frequency (Fig. 4BI). The injected current and the voltage responses during low-frequency stimulation (Fig. 4B2) contained large transients, whereas the current and voltage waveforms during high-frequency stimulation (Fig. $4 B 3, B 4$ ) contained substantial steady components.

A notable difference between conductance and current clamp was that at high stimulus frequencies, the firing rate evoked under conductance clamp was considerably lower. The maximum firing evoked during $1200 \mathrm{~Hz}$ stimulation under conductance clamp, for example, was $\sim 10 \mathrm{~Hz}$ (Fig. $4 B 1$ ), whereas the maximum rate evoked at $1500 \mathrm{~Hz}$ under current clamp was $80 \mathrm{~Hz}$ (Fig. 4A1). This occurred because the injected current under conductance clamp decreased as the membrane potential approached the reversal potential $(0 \mathrm{mV})$ for the PSC. Hence, the average membrane potential during stimulation under conductance clamp was less than the potential under current clamp at the same stimulus frequency. In eight neurons, the firing evoked during $1200 \mathrm{~Hz}$ stimulation did not exceed $30 \mathrm{~Hz}$. The CFs of three of these neurons, estimated from their location in NL (Lippe, 1987), were $>2000 \mathrm{~Hz}$. Because the evoked firing rates were substantially lower than those evoked in the owl NL during in vivo acoustic stimulation ( $\sim 190 \mathrm{~Hz}$; Carr and Konishi, 1990), additional experiments were performed to examine the optimal conditions for firing.

During high-frequency stimulation, the firing rate evoked in NL neurons was increased by using protocols with large PSCs. In the following, stimuli were applied under conductance clamp but similar results were obtained under current clamp. Figure $5 A$ plots the average evoked firing rate against the number of simulated NM cells during $1200 \mathrm{~Hz}$ stimulation. Each curve represents the relation obtained with different conductance amplitudes. The maximum firing rate evoked with a $32 \mathrm{nS}$ unitary conductance change was $-200 \mathrm{~Hz}$ (open circles). This was nearly sevenfold greater than that evoked with a $4 \mathrm{nS}$ unitary conductance change (solid circles).

Protocols containing large PSCs were more efficient at evoking high firing rates than protocols containing small PSCs. In Figure $5 A$ the dotted line connects data points in which the total conductance change (number of NM cells $\times$ amplitude of unitary conductance) was equal. For an equivalent total conductance change, progressively higher discharge rates were obtained with larger PSCs. Moreover, with a larger unitary conductance change, the maximum firing rate was attained with fewer simulated NM cells.

For an equivalent total conductance change, the time course of the injected current varied substantially with the number of NM cells. For example, the current generated when the protocol contained $5 \mathrm{NM}$ cells ( $32 \mathrm{nS}$ unitary conductance change) contained large transients (Fig. $5 B$ ), whereas the current generated when the protocol contained $40 \mathrm{NM}$ cells ( $4 \mathrm{nS}$ unitary conductance change) was predominantly steady (Fig. $5 \mathrm{C}$ ).

\section{Optimal stimuli for phase-locking}

The protocol also was used to examine the ability of NL cells to phase-lock to stimuli. Phase-locking was quantified using vector strength analysis (Goldberg and Brown, 1969) (see Materials and Methods). A vector strength of 1 indicates perfect phase-locking, whereas a value of zero indicates that the evoked action potentials occurred randomly throughout the stimulus cycle. The aims of the following experiments were (1) to examine the variation of phaselocking with stimulus frequency, and (2) to determine the stimulus conditions that are optimal for phase-locking. Unless specified otherwise, the data presented below were obtained under current clamp, and the discharge rate of each simulated NM cell was $250 \mathrm{~Hz}$.

Phase-locking decreased with stimulus frequency. The curves in Figure $6 A$ plot the relation between vector strength and stimulus frequency under various conditions. The relation obtained when the amplitude of the computer-generated PSC $(0.2 \mathrm{nA})$ was comparable with the mean amplitude of the stimulus-evoked PSC also is shown (solid triangles). Examining phase-locking with small 

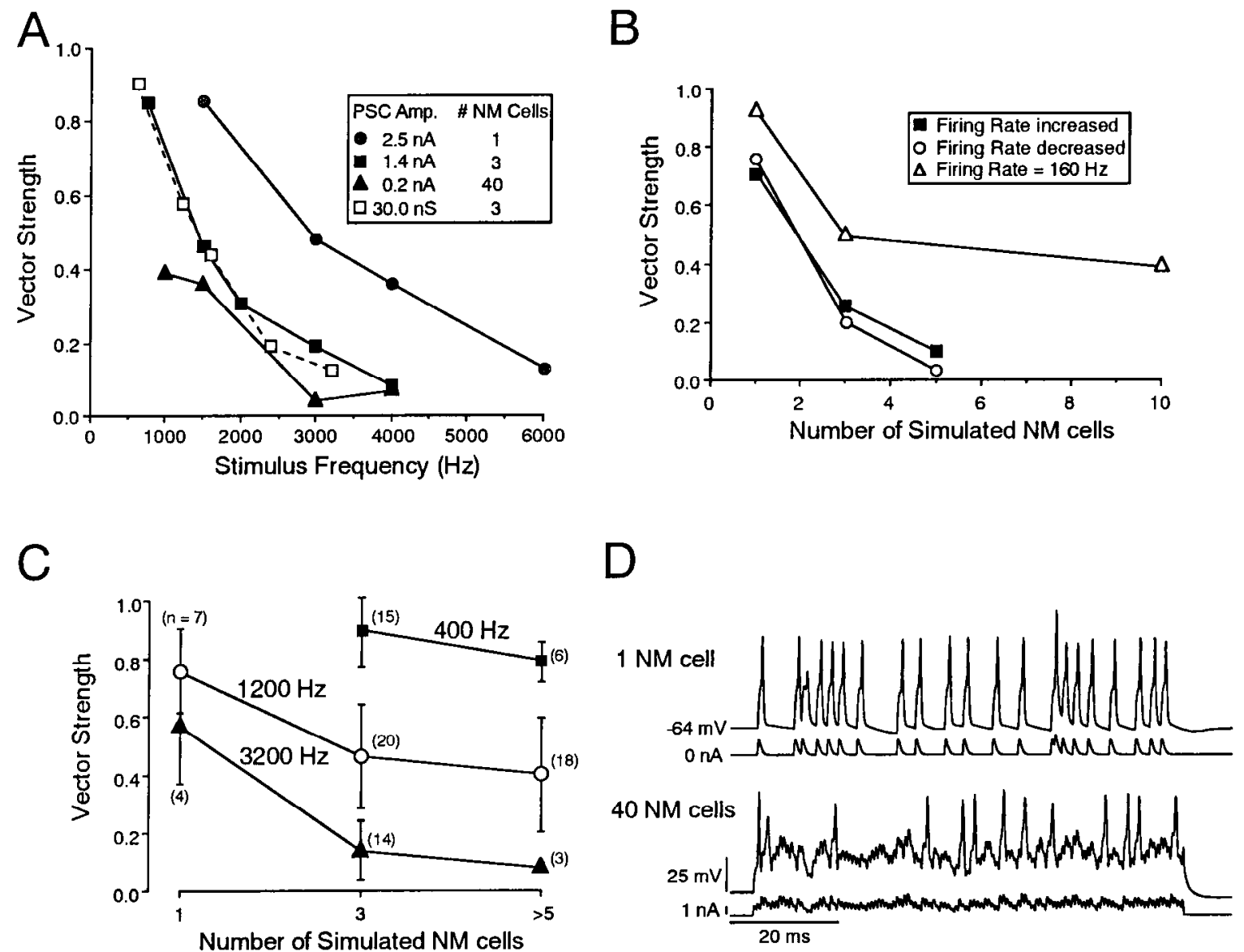

Figure 6. Optimal stimuli for phase-locking. A, Plot of vector strength versus stimulus frequency for a range of PSC amplitudes. Solid points were obtained under current clamp. Open squares were obtained under conductance clamp. Plots were obtained during stimulation with 1 (circles), 3 (squares), and 40 (triangles) NM cells. B. Plot of vector strength during $1200 \mathrm{~Hz}$ stimulation versus number of NM cells under three conditions in three NL cells. Stimuli were applied under current clamp. Solid squares show the relation when the amplitude of the computer-generated unitary PSC was $0.5 \mathrm{n}$ A. The evoked firing rate increased with the number of NM cells (data not shown). Open circles show the relation when the amplitude of the unitary PSCs decreased with increasing number of NM cells (PSC amplitude $=4 \mathrm{n} \mathrm{A}$ /number of NM cells). The evoked firing rate also decreased. Open triangles show the relation ohtained when the amplitude of the unitary PSCs was adjusted so that the firing rate was maintained at $160 \mathrm{~Hz}$. C, Pooled plot of mean ( \pm SD) vector strength versus number of NM cells during 400,1200 , and $3200 \mathrm{~Hz}$ stimulation. The number of NL cells from which the data points were obtained is shown in parentheses. Data obtained when the protocol contained five or more NM cells (range 5-100 NM cells) were pooled. $D$, Voltage and current traces obtained when the stimulation protocol contained 1 (top traces) and 40 (bottom traces) NM cells. Records were from the cell shown in $A$.

PSCs proved difficult because the firing rates evoked at high stimulus frequencies were often very low. For this cell, however, $>100 \mathrm{~Hz}$ firing was attained by increasing the number of NM cells to 40 at all stimulus frequencies. The vector strength was 0.4 during $1 \mathrm{kHz}$ stimulation and decreased to near zero during $3 \mathrm{kHz}$ stimulation. The vector strengths obtained under these conditions were considerably lower than those documented in vivo in NI. (Carr and Konishi, 1990) and MSO neurons (Crow et al., 1978; Yin and Chan, 1990). The following experiments, therefore, were performed to examine stimulus conditions that were more favorable for phase-locking.

Phase-locking during high-frequency stimulation improved when the protocol contained few NM neurons. The additional curves in Figure $6 \mathrm{~A}$ show the relations between vector strength and stimulus frequency when the number of simulated NM neurons was varied. The amplitudes of the PSCs were adjusted so that the evoked firing rate exceeded $100 \mathrm{~Hz}$ in all cases. During 1000 $\mathrm{Hz}$ stimulation, the vector strength obtained when the protocol contained 3 NM cells (1.4 n A unitary PSCs; solid squares) was $>0.8$; this was twice the vector strength obtained with $40 \mathrm{NM}$ cells
(0.2 n A unitary PSCs; triangles). At higher stimulus frequencies, reliable phase-locking was obtained only when the protocol contained very few NM cells. During $3000 \mathrm{~Hz}$ stimulation, the vector strength obtained during stimulation with one NM cell $(2.5 \mathrm{nA}$ unitary PSC; solid circles) was $\sim 0.5$; that obtained with $40 \mathrm{NM}$ cells (triangles) was nearly zero.

The decrease in vector strengths was correlated primarily with the number of NM cells and not directly with the evoked firing rate or the size of the PSCs. Figure $6 B$ plots vector strength against the number of NM cells under three conditions. Data were obtained under current clamp during $1200 \mathrm{~Hz}$ stimulation. In the first condition (solid squares), the amplitude of the PSCs was 0.5 $\mathrm{n} \mathrm{A}$. The evoked firing rate increased from 160 to $300 \mathrm{~Hz}$ when the number of simulated NM cells was increased from one to five cells. In the second condition (open circles), the PSC amplitudes decreased with increasing number of NM cells (PSC amplitude = $4 \mathrm{nA}$ /number of NM cells); the evoked firing rate decreased from 170 to $60 \mathrm{~Hz}$. In the third condition (open triangles), the amplitude of the unitary PSCs was adjusted (increased) so that the evoked 
firing was maintained at $160 \mathrm{~Hz}$ as the number of NM cells was increased. Under all three conditions, the vector strength decreased with increasing number of simulated NM cells.

As the stimulus frequency was increased, phase-locking comparable with that observed during in vivo acoustic stimulation in NL (Carr and Konishi, 1990) and MSO (Crow et al., 1978; Yin and Chan, 1990) neurons was attained only when the protocol contained very few NM cells. Figure $6 C$ plots vector strengths against the number of NM cells ( 1,3 , and $\geq 5$ cells) for a range of stimulus frequencies. Each data point is the average ( $\pm S D$ ) vector strength compiled from several cells ( $n$ shown in parentheses). The PSC amplitudes were such that the evoked firing rate exceeded $100 \mathrm{~Hz}$ (mean $218 \pm 68 \mathrm{~Hz}$ ) during $400 \mathrm{~Hz}$ stimulation and $40 \mathrm{~Hz}$ (mean $102 \pm 57 \mathrm{~Hz}$ ) during $1200 \mathrm{~Hz}$ stimulation. At low stimulus frequencies $(400 \mathrm{~Hz}$; squares), the vector strengths were high and decreased only slightly as the number of NM cells in the protocol was increased. The mean value when the protocol contained 3 and $\geq 5 \mathrm{NM}$ cells was $0.9 \pm 0.1$ and $0.8 \pm 0.1$, respectively. In one cell that was stimulated with a protocol containing 100 simulated NM cells, the vector strength was 0.9 . These values are comparable with those obtained in MSO neurons $(>0.8)$ (Crow et al., 1978; Yin and Chan, 1990) during acoustic stimulation at comparable frequencies. During $1200 \mathrm{~Hz}$ stimulation, vector strengths $(0.8 \pm 0.1)$ comparable with those in vivo ( 0.8) (Crow et al., 1978; Carr and Konishi, 1990; Yin and Chan, 1990) were attained only when the protocol contained 1 NM cell. With three NM cells, the vector strength dropped to 0.5 \pm 0.2 . Similarly, during $3200 \mathrm{~Hz}$ stimulation, only the vector strength $(0.6 \pm 0.2)$ oblained with $1 \mathrm{NM}$ cell was comparable with those measured in owls $(\sim 0.6$; Carr and Konishi, 1990). With three NM cells, the vector strength decreased to $0.1 \pm 0.1$.

Inspection of voltage traces (Fig. $6 D$, top traces) obtained during $1500 \mathrm{~Hz}$ stimulation with 1 and $40 \mathrm{NM}$ cells shows that with 1 NM cell, the membrane potential repolarized to near resting potential after each action potential. In contrast, with $40 \mathrm{NM}$ cells, there was a sustained depolarizing shift in the membrane potential because of summation of the computer-generated PSPs.

The vector strengths obtained under conductance clamp were similar to those obtained under current clamp $(n=4)$. Figure $6 A$ (open squares) shows the data obtained under conductance clamp with three NM cells in the stimulus protocol. The evoked firing rates were comparable with those obtained under current clamp. The plot of vector strength versus stimulus frequency superimposes with the plot obtained during stimulation with three NM cells under current clamp (solid squares). As with current clamp, vector strength decreased with stimulus frequency and increased when the stimulus protocol contained few NM cells that generated large PSCs (data not shown).

\section{Variation of firing rate and phase-locking with other stimulus parameters}

The algorithm used in generating the injected current was chosen to examine firing and phase-locking under simplified conditions. To ensure that the results are generalizable to more complex stimulus waveforms that may arise during acoustic stimulation, several modifications were made in the stimulus protocols.

In addition to the number of NM cells and the stimulus frequency, the firing responses of NL neurons also may vary with the AFR of the simulated NM neurons. In vivo recordings in chicks reveal that NM neurons can sustain firing ranging from 100 to 500 $\mathrm{Hz}$ (Warchol and Dallos, 1991). Figure 7 shows the dependence of evoked firing rate (solid triangles) and vector strength (open cir-

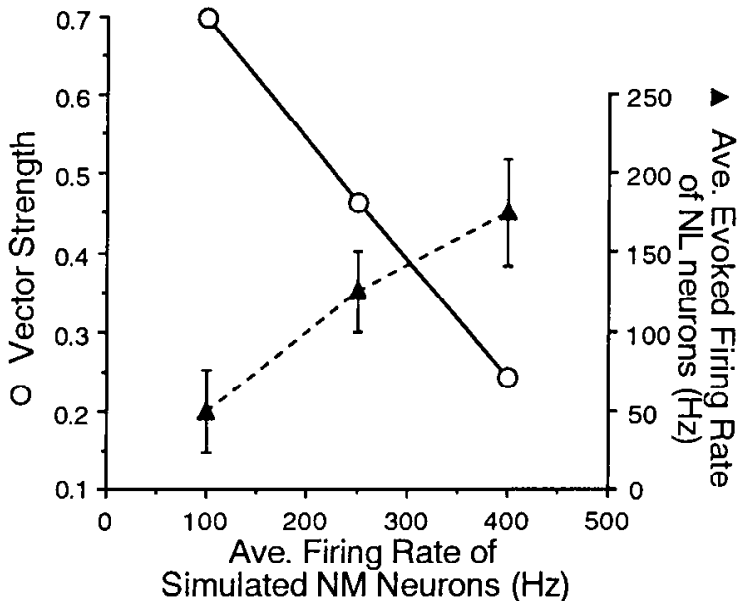

Figure 7. Effects of NM-cell firing rate on NL firing rate and phaselocking. Plot of vector strength (left ordinate, open circles) and mean ( \pm SD) firing rate (right ordinate, solid triangles) versus the firing rate of simulated NM cells. The protocol contained three simulated NM cells that produced $1.4 \mathrm{n}$ A PSCs. Stimulus frequency was $1500 \mathrm{~Hz}$. Stimuli were applied 50 times under current clamp.

cles) on the AFR of each NM neuron. Stimulation was with three NM cells; the PSCs (amplitude, $1.4 \mathrm{nA}$ ) were applied under current clamp. Stimulus frequency was $1500 \mathrm{~Hz}$. Increasing the AFR of each simulated NM neuron increased the evoked firing rate. However, there was an accompanying decrease in the vector strengths. Increasing the NM discharge rate, like increasing the number of NM cells, caused more summation of the voltage and current waveforms (data not shown).

The temporal characteristics of NM firing also may affect NL firing. For simplicity, the intervals between each simulated NM action potential in the stimulus protocols were assumed to be distributed uniformly around a mean interval (see Materials and Methods). The ISIs of auditory neurons often are described as a Poisson or quasi-Poisson distribution (Manley and Robertson, 1979; Klinke and Pause, 1980; Geisler, 1981; Manley et al., 1991). The firing rate and the vector strengths obtained using a Poisson process to determine the ISIs of the simulated NM cells were not systematically different from those obtained using a uniform distribution ( $n=3$; data not shown).

Finally, the protocol was modified so that the amplitude of the unitary PSCs varied with the ISIs of the simulated NM cells. In NM neurons, the amplitude of the stimulus-evoked PSCs was found to vary with the instantaneous stimulus rate (Raman and Trussell, 1993). A similar phenomenon appears to exist in NL neurons (A. D. Reyes and W. J. Spain, unpublished observations). Incorporating frequency-dependent variations in PSC amplitudes into the protocol caused an additional decrease in the evoked firing rate, particularly during high-frequency stimulation (data not shown). The net effect was to decrease the average current amplitude per cycle as given by Equation 5 .

\section{Modulation of firing during time-delayed stimulation with two trains}

The synaptic current reaching the soma of NL neurons during binaural stimulation was mimicked by constructing two sets of trains, representing inputs from ipsilateral and contralateral NM. As above, the impulses of each train were phase-locked to a specified stimulus frequency. The two sets of trains then were summed before injection. To simulate interaural time delays in 


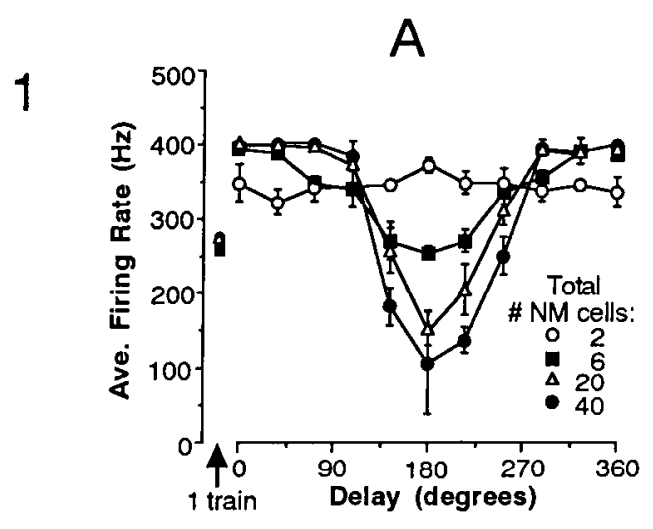

$400 \mathrm{~Hz}, 40 \mathrm{NM}$ cells
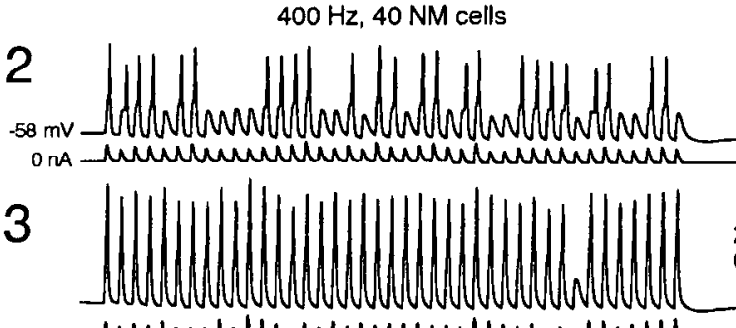

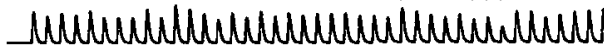

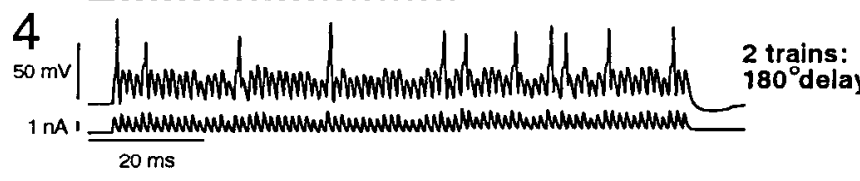

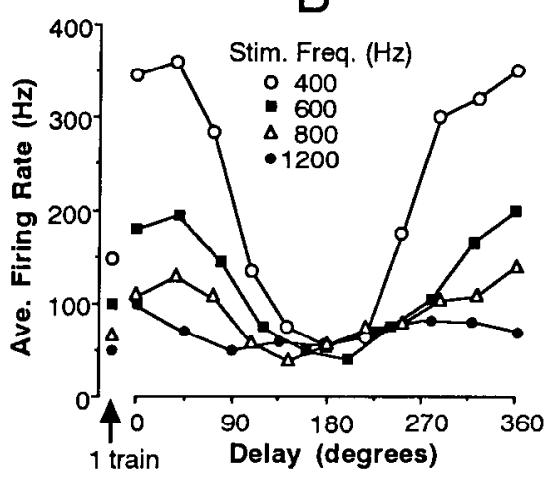

$1200 \mathrm{~Hz}, 6 \mathrm{NM}$ cells

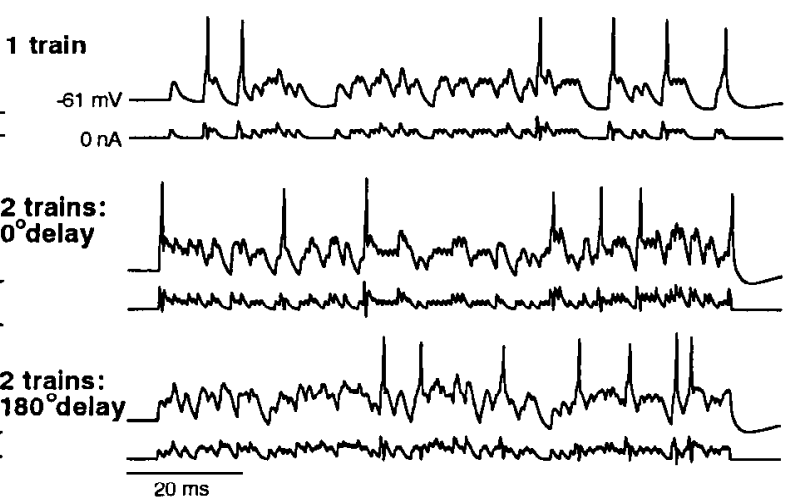

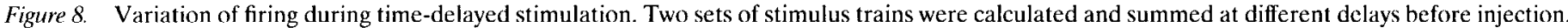

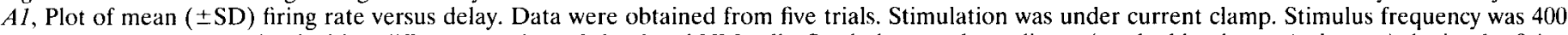

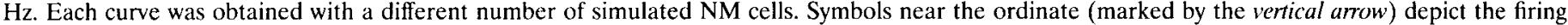

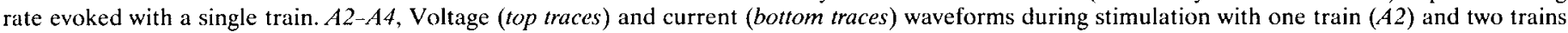

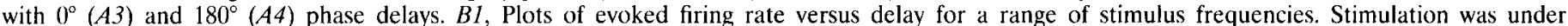

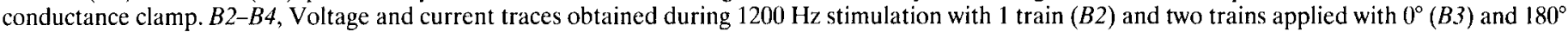
(B4) phase delays. The protocol contained six NM cells.

the arrival of stimulus to the two ears, the onset of one of the trains was delayed systematically before summation and injection.

As was observed in vivo (Carr and Konishi, 1990), there was an optimal delay that evoked the greatest firing. Figure $8 \mathrm{Al}$ (solid circles) plots the firing rate evoked with $0.2 \mathrm{n}$ A PSCs as a function of delay. Stimulus frequency was $400 \mathrm{~Hz}$. Each train contained 20 simulated NM cells (40 NM cells total). Data shown were obtained under current clamp, although similar results were obtained under conductance clamp. The greatest firing rates were obtained when the delays between trains were small. At these delays, the firing rate exceeded that evoked with a single train (symbols on left). As the delay was increased, the evoked firing rate decreased. At $180^{\circ}$ phase delay, the evoked firing rate was less than that evoked with a single train.

The voltage and current waveforms became more steady as the delays between trains increased. Figure $8 A 2-A 4$ compares the voltage records during stimulation with a single train (Fig. 8A2) and during stimulation with two trains introduced with zero (Fig. $8 A 3$ ) and $180^{\circ}$ (Fig. $8 A 4$ ) phase delays. The voltage and current waveform obtained during two-train stimulation with no delay contained large transients that were well segregated in time. The amplitudes of these transients were greater than those during stimulation with a single train. In contrast, lemporal summation occurred when the delay between trains was $180^{\circ}$. In effect, intro- ducing two stimulus trains with a $180^{\circ}$ phase shift is analogous to doubling the stimulus frequency.

Decreasing the number of NM neurons in the protocol decreased the delay-dependent modulation of firing. The additional curves in Figure $8 A 1$ plot firing rate versus delay for a range of NM cell number. The PSC amplitudes ( $4 \mathrm{nA}$ /number of NM cells) were adjusted so that the firing rate evoked with one train (symbols on left) were comparable in all cases. The difference between the maximum and minimum firing rates systematically decreased as the total number of NM cells was decreased from 40 to 2 NM cells. With two NM cells (open circles), the firing did not vary with delay.

Modulation of firing decreased with increasing stimulus frequency. Figure $8 B 1$ plots the relations obtained during stimulation at $400,600,800$, and $1200 \mathrm{~Hz}$ for another cell. Data shown were obtained under conductance clamp, but similar observations were made under current clamp. The stimulation protocol was with a total of six NM cells, each of which produced a $30 \mathrm{nS}$ unitary synaptic conductance. As the frequency increased, the difference between maximum and minimum firing rate decreased systematically. In general, modulation of firing did not occur when the stimulus frequencies exceeded $1200 \mathrm{~Hz}$ : only 3 of $14 \mathrm{NL}$ neurons exhibited modulation during $1200 \mathrm{H} \angle$ stimulation. Figure $8 B 2-B 4$ shows voltage and current waveforms obtained during $1200 \mathrm{~Hz}$ 

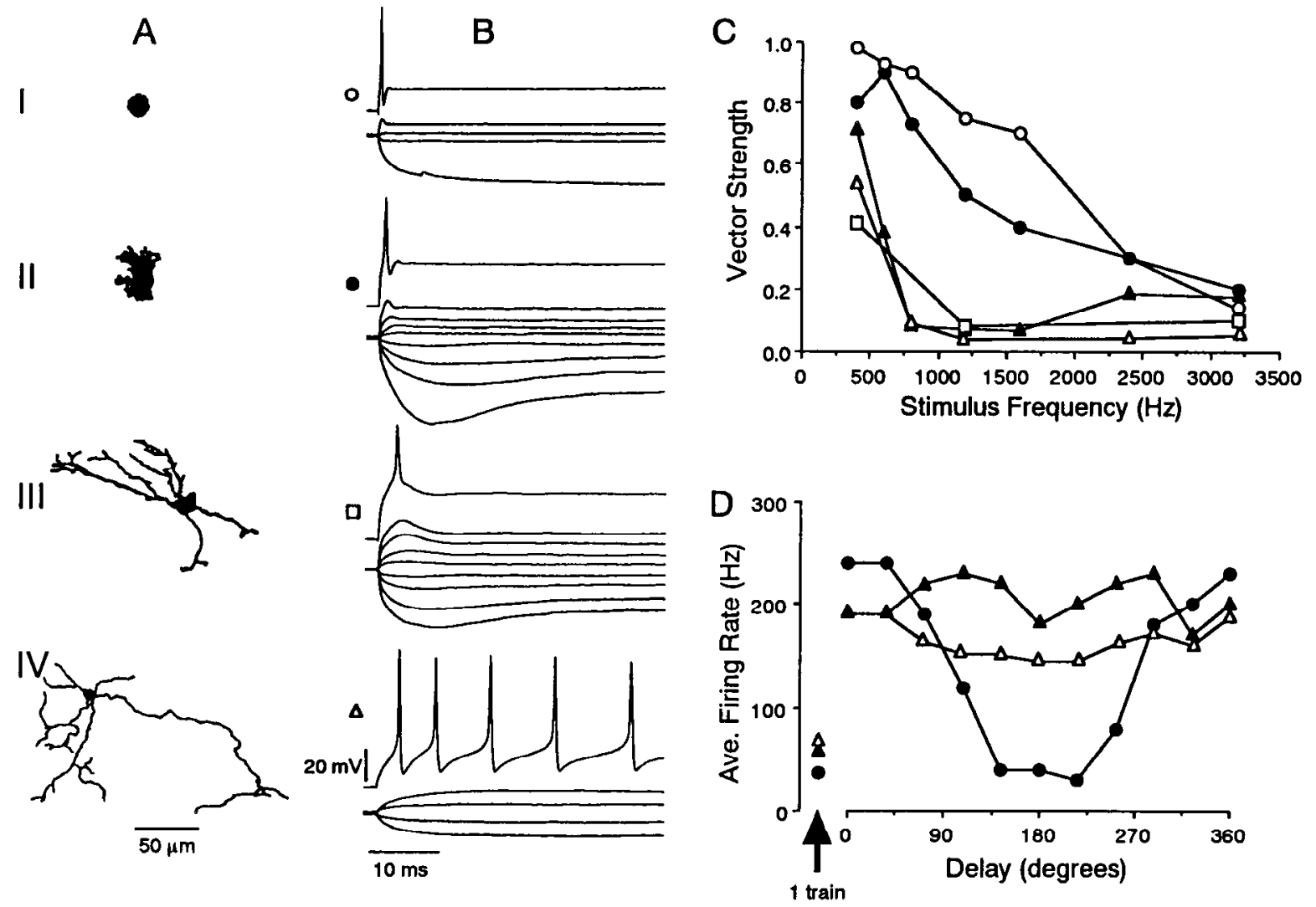

Figure 9. Phase-locking and time-dependent modulation of firing in other cell types. $A, B$, Cells labeled with biocytin $(A)$ and their corresponding voltage responses to sub- and suprathreshold current steps $(B)$. Traces during suprathreshold current steps were offset for clarity. $C$, Plot of vector strength versus stimulus frequency for the labeled neurons and for an unlabeled neuron from the lagenar region (solid triangles). Vector strengths for NM and NL were averaged from the vector strengths of three and seven cells, respectively. The evoked firing rate in all cases exceeded $70 \mathrm{~Hz} . D$, Plots of evoked firing rate versus delay during two train stimulation for an NL neuron (solid circles), cell IV (open triangles), and the unlabeled lagenar neuron (solid triangles). The protocols contained six presynaptic cells.

stimulation with a single train and with two trains introduced with $0^{\circ}$ and $180^{\circ}$ phase delays. The waveforms obtained with phase delays of $0^{\circ}$ and $180^{\circ}$ contained comparable steady components. Modulation at high-frequency stimulation was not improved by varying the number of NM cells or the PSC amplitude (data not shown).

\section{Responses of other cell types to the stimulus protocol}

To determine whether the firing responses evoked with the stimuli were unique to NL neurons, the stimulus protocols also were applied to other cell types. Figure $9 A$ shows representative cells labeled with biucytirl: cell I was from NM; cell II was from the rostral three-fourths of NL; cell III was from the caudolateral region of NL; and cell IV was from nucleus vestibularis descendalis. Figure $9 B$ compares the responses of the cells during current-step injections. NM neurons, like NL neurons, exhibited strong outward rectification (Reyes et al., 1994). Cell III exhibited less outward rectification: the voltage responses to depolarizing and hyperpolarizing steps were less asymmetric, and the humps during depolarizing steps were broader. Cell IV did not exhibit outward rectification and fired repetitively during stimulation with a suprathreshold current step. Note also that the times-to-peak of the depolarizing voltage responses in cells III and IV were considerably longer than those of neurons in NM or in the rostral region of $\mathrm{NL}$.

Only neurons that exhibited strong, rapidly activating outward rectification were able to phase-lock reliably during high- frequency stimulation. Figure $9 C$ plots vector strength against the stimulus frequency for the different cell types. In all cases, the stimulus protocol contained three simulated presynaptic cells. Curves obtained from NM and NL were compiled from three and seven neurons, respectively. Vector strengths of cells III and IV were clearly less than those obtained for the NM and the anterior NL neurons, particularly during high-frequency stimulation. The relation for a cell from the lagenar region that also fired repetitively is included (solid triangles).

The firing of cells that lacked strong, rapidly activating outward rectification was not modulated during time-delayed stimulation with two trains. Figure $9 D$ plots the firing as a function of delay for an NL neuron (solid circles), cell IV (open triangles), and the lagenar neuron (solid triangles). All protocols contained a total of six NM cells and the stimulus frequency was $400 \mathrm{~Hz}$. The difference between maximal and minimal firing rate was considerably less for cell IV and the lagenar neuron than for the NL neuron.

\section{DISCUSSION}

In this study, we examined the responses of NL neurons to stimuli that mimicked the synaptic inputs during monaural and binaural acoustic stimulation. Using a computer, the current generated by the summed activities of NM neurons was calculated and injected into the cell. We demonstrated that the optimal stimuli for maintaining high discharge rates and reliable phase-locking contained few NM neurons that generated large PSCs. We also showed that 
NL firing was modulated by two trains applied at different delays. Because the protocol effectively excluded the contribution of the neural network, modulation was necessarily attributable to the intrinsic membrane properties of the cell.

The discharge patterns of the simulated NM cells replicated two features of NM firing: (1) their impulses were phase-locked, and (2) their average discharge rates were within the range observed in vivo during acoustic stimulation (Warchol and Dallos, 1990). To examine phase-locking under ideal conditions, jitter in NM firing was not incorporated into the protocol. The transient, high-frequency discharge at the start of acoustic stimulus (Warchol and Dallos, 1990) also was excluded: as suggested by Figure 7 , this burst would increase the evoked firing rate but decrease phase-locking. The distributions of NM ISIs were either uniform or Poisson; both produced comparable responses.

The computer-generated PSCs and PSPs were adjusted to match the stimulus-evoked PSCs and PSPs. Because the stimulusevoked PSPs were measured at the soma, their shape and size reflected any transformations that occurred in the dendrites. The spike initiation region likely is in the initial segment (Stuart and Sakmann, 1994) or at the first node of Ranvier for rostrally located NL neurons (Carr and Boudreau, 1993a), that is, downstream from both the dendrites and soma. Therefore, computergenerated and stimulus-evoked PSPs should have similar effects on firing. Although the PSCs were evoked in an all-or-none manner with minimal stimulation of afferents, the measured amplitudes represent upper limit estimates of the unitary PSC amplitude. Our conclusions, however, will not be affected if the true amplitudes are smaller.

The computer-generated PSCs were injected under current or conductance clamp. Conductance clamp may be more appropriate for neurons with high CFs because their short dendrites likely make them more electrotonically compact. Either type of stimulus produced comparable phase-locking and modulation of firing during time-delayed stimuli. The evoked firing was less under conductance clamp because the decrease in input resistance and "ciriving force" attenuated the voltage responses.

\section{Maintenance of high discharge rates, phase-locking, and sensitivity to time-delayed stimuli}

Strong, rapidly activating, outward rectification caused NL neurons to be more responsive to transient than to steady stimuli. The outward rectification has a rapid onset and is relatively persistent. Similar rectification has been observed in other auditory neurons (Wu and Oertel, 1984; Wu and Kelly, 1991; Banks and Smith, 1992; Zhang and Trussell, 1994; Smith, 1995) and is attributable to a rapidly activating, slowly inaclivaling outward current (Manis and Marx, 1990; Reyes et al., 1994). During steady current injection, NL neurons fired only a single action potential because the outward current becomes tonically active after a short delay and prevents further threshold crossings. In contrast, repetitive stimulation with transients allows the outward current to deactivate in the interstimulus intervals and hence permit firing during successive stimulus cycles.

The firing evoked with the stimulus protocol was greatest during low-frcquency stimulation because the injected current contained large transients that were well segregated in time. During high-frequency stimulation, the evoked firing rate was low because temporal summation of the PSCs increased and the injected current became predominantly steady. The number of threshold crossings was reduced because tonic activation of the outward current attenuated the voltage responses in the depolarizing di- rection and increased firing threshold. The elevated threshold likely was attributable to a decrease in the net inward ionic current (Bennett et al., 1970) caused by tonic activation of the outward current and partial inactivation of the sodium conductance. Using a protocol that contained few and large PSCs increased firing, because the injected current contained larger transients and less steady components. Firing rates comparable with those documented in vivo (Carr and Konishi, 1990) were evoked only with protocols containing very few NM cells.

Reliable phase-locking was strongly dependent on the stimulus waveform. During low-frequency stimulation, the membrane potential contained large transients that peaked at cach cycle and were near resting potential between cycles. Hence, the probability of an action potential crossing threshold was greatest near the start of each cycle. During high-frequency stimulation, the peaks did not occur necessarily at a certain phase of the cycle because of temporal summation of the PSPs. Phase-locking decreased because the probability of evoking action potentials was comparable throughout the stimulus cycle.

Like discharge rates, phase-locking during high-frequency stimulation was improved by using protocols that contained few NM neurons and large PSCs. This reduced temporal summation of the current and voltage waveforms. Vector strengths comparable with those observed in vivo (Carr and Konishi, 1990; Yin and Chan, 1990) were obtained only with protocols containing few NM cells that generated large PSCs. This is consistent with modeling studies (Rothman et al., 1994) that suggest that suprathreshold PSCs produce the most reliable phase-locking in spherical bushy cells.

The optimal stimuli for firing and phase-locking in these embryonic (E19-E21) NL neurons are unlikely to differ substantially in older animals. The sub- and suprathreshold membrane properties of embryonic NL neurons are similar to those of NL neurons in posthatch chicks (postnatal days 1-6; Reyes et al., 1991). Because the rapidly activating outward rectification appears to be crucial for phase-locking, it also should be present in comparable amounts in adult NL neurons. Hence, the optimal stimulus protocol in adult NL neurons also would contain few and large PSCs.

The sensitivity of NL neurons to time-delayed stimuli was replicated in vitro. The evoked firing was modulated by phase delays in the application of two stimulus trains. This occurred because the relative amount of transient and steady components varied under each stimulus condition. Firing was greatest with zero delay because the amplitude of the transients was largest. Firing evoked with $180^{\circ}$ phase delay was less than that evoked with a single train because the composite current was predominantly steady. These results suggest that modulation of firing, at least for low frequencies, is not critically dependent on inhibitory inputs.

Modulation was consistently observed only during stimulation at frequencies less than $\sim 1200 \mathrm{~Hz}$. At higher stimulus frequencies, the injected current was equally steady at all delays. The range of frequencies at which modulation occurred is comparable with that in mammals (Yin and Chan, 1990) but is substantially less than that in owls (up to $6.5 \mathrm{kHz}$; Carr and Konishi, 1990). This discrepancy may reflect further specializations in the owl auditory system.

The difference between the firing rate at the favorable and unfavorable delay was greatest when the protocol contained many small PSCs. Extensive summation of PSCs at the nonoptimal delay was crucial for tonic activation of the outward current and, thus, for attenuation of firing. This contradicts the optimal stimuli for high firing rates and phase-locking, which require few and 


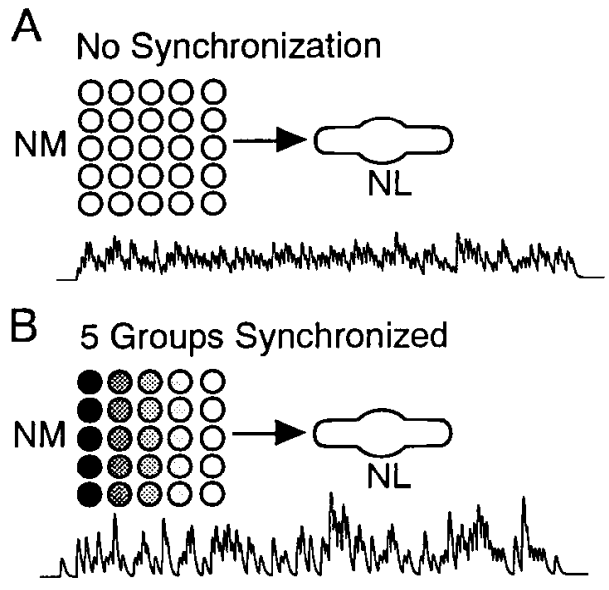

Figure 10. Effects of synchrony on current waveform. Schematic shows 25 $N M$ cells projecting to a single $N L$ neuron. $A$, Current produced when NM neurons fire action potentials that are independent of each other. Stimulation frequency was $1200 \mathrm{~Hz}$. PSC amplitude was $0.2 \mathrm{nA}(\alpha=3) . B$, Current produced when the firing of five groups of five NM neurons was synchronized.

large PSCs to minimize temporal summation. Therefore, there is a trade-off between binaural modulation of firing rate versus phase-locking and maintenance of high firing rates. During lowfrequency stimulation, in which modulation was consistently observed, the PSC number was not crucial for firing rate or phaselocking (Fig. $6 \mathrm{C}$ ). At higher frequencies, binaural modulation may be maintained but at the expense of phase-locking and firing at high rates. It is interesting to note that NM cells in the bird and bushy cells in the mammalian cochlear nucleus are innervated by only a few eighth nerve afferents that generate very large PSPs and PSCs (Hackett et al., 1982; Jackson and Parks, 1982; Oertel, 1983; Zhang and Trussell, 1994). These cells transmit phase-locked information but, unlike NL neurons, do not process binaural information directly.

\section{Functional implications}

Strong, rapidly activating outward rectification was crucial for phase-locking: neurons lacking this property were unable to phase-lock as reliably as NL or NM neurons. Because of its rapid onset, the rectification rapidly repolarized the membrane potential and minimized temporal summation (Manis and Marx, 1991; Reyes et al., 1994). However, the degree of summation ultimately depends on the characteristics of the synaptic input: with many small PSCs, summation still occurs regardless of the magnitude or time course of the outward rectification.

The optimal stimulus protocol for maintaining high discharge rates and reliable phase-locking during high-frequency stimulation contained few large PSCs. This contradicts anatomical and physiological data. The estimated number of NM neurons that project to an NL neuron ranges from 20 to 50 in adult chicks (S. Young and E. Rubel, unpublished observations) and from 45 to 150 in adult barn owls (Carr and Boudrcau, 1993b).

It is conceivable that neurons with high CFs receive fewer and larger PSCs. Anatomically, these neurons have a smaller dendritic surface area than neurons with low CFs (Smith and Rubel, 1979; Smith, 1981). However, this would contradict our data showing that the measured PSCs are equally small throughout the tonotopic axis (Fig. 3). Nevertheless, there are posthatch changes in dendritic morphology, and the possibility of associated changes in the number and amplitude of PSCs cannot be excluded.
Another way of simultaneously maintaining high discharge rates and phase-locking during high-frequency stimulation is by synchronizing NM afferents. Figure 10 shows a schematic of an NL neuron innervated by $25 \mathrm{NM}$ cells, each of which generates a $0.2 \mathrm{n}$ A PSC. If, during $1200 \mathrm{~Hz}$ stimulation, the NM neurons fire independently of each other, summation occurs and the composite current has a large sustained component (Fig. 10A). If five groups of five NM neurons are synchronized, however, there effectively will be five $1 \mathrm{n}$ A PSCs appearing in NL (Fig. 10B). In owls, an eighth nerve fiber projects to three to six NM neurons (Carr and Boudreau, 1991). Because synaptic potentials in NM are large (Hackett et al., 1982; Zhang and Trussell, 1994), the NM neurons may fire synchronously.

\section{REFERENCES}

Banks MI, Smith PH (1992) Intracellular recording from neurobiotinlabeled cells in brain slices of the rat medial nucleus of the trapezoid body. J Neurosci 12:2819-2837.

Bennett MVL, Hille B, Obara S (1970) Voltage threshold in excitable cells depends on stimulus waveform. J Neurophysiol 33:585-594.

Carr CE, Boudreau RE (1991) Central projections of auditory nerve fibers in the barn owl. J Comp Neurol 314:306-318.

Carr CE, Boudreau RE (1993a) An axon with a myelinated initial segment in the bird auditory system. Brain Res 628:330-334.

Carr CE, Boudreau RE (1993b) Organization of the nucleus magnocellularis and the nucleus laminaris in the barn owl: encoding and measuring interaural time differences. J Comp Neurol 334:337-355.

Carr CE, Konishi M (1990) A circuit for detection of interaural time differences in the brain stem of the barn owl. J Neurosci 10:3227-3246.

Colburn HS, Han Y, Culotta CP (1990) Coincidence model of MSO responses. Hear Res 49:335-346.

Crow G, Rupert A, Moushegian G (1978) Phase locking in monaural and binaural medullary neurons: implications for binaural phenomena. $\mathrm{J}$ Acoust Soc Am 64:493-501.

Geisler CD (1981) A model for discharge patterns of primary auditorynerve fibers. Brain Res 212:198-201.

Goldberg JM, Brown PB (1969) Response of binaural neurons of dog superior olivary complex to dichotic tonal stimuli: some physiological mechanisms of sound localization. J Neurophysiol 32:613-636.

Grothe B, Sanes DH (1994) Synaptic inhibition influences the temporal coding properties of medial superior olivary neurons: an in vitro study. J Neurosci 14:1701-1709.

Hackett JT, Jackson H, Rubel EW (1982) Synaptic excitation of the second and third order auditory neurons in the avian brain stem. Neuroscience 7:1455-1469.

Horikawa K, Armstrong WE (1988) A versatile means of intracellular labelling: injection of biocytin and its detection with avidin conjugates. J Neurosci Methods 25:1-11.

Jackson H, Parks TN (1982) Functional synapse elimination in the developing avian cochlear nucleus with simultaneous reduction in cochlear nerve branching. J Neurosci 2:1736-1743.

Inseph AW, Hyson RI, (1993) Coincidence detection by hinaural neurons in the chick brainstem. J Neurophysiol 69:1197-1211.

Lachica EA, Rubsamen R, Rubel EW (1994) GABAergic terminals in nucleus magnocellularis and nucleus laminaris originatc from the supcrior olivary nucleus. J Comp Neurol 348:403-418.

Lippe WR (1987) Shift of tonotopic organization in brain stem auditory nuclei of the chicken during late embryonic development. Hear Res 25:205-208.

Lippe WR, Rubel EW (1985) Ontogeny of tonotopic organization of brain stem auditory nuclei in the chicken: implications for development of the place principle. J Comp Neurol 237:273-289.

Manis PB, Marx SO (1991) Outward currents in isolated ventral cochlear nucleus neurons. J Neurosci 11:2865-2880.

Manley GA, Robertson D (1976) Analysis of spontaneous activity of auditory neurones in the spiral ganglion of the guinea-pig cochlea. J Physiol (Lond) 258:323-336.

Manley GA, Kaiser A, Brix J, Gleich O (1991) Activity patterns of primary auditory-nerve fibres in chickens: development of fundamental properties. Hear Res 57:1-15. 
Moushegian G, Rupert A, Gidda JS (1975) Functional characteristics of superior olivary neurons to binaural stimuli. J Neurophysiol 38:1037-1048.

Oertel $D$ (1983) Synaptic responses and electrical properties of cells in brain slices of the mouse anteroventral cochlear nucleus. J Neurosci 13:2043-2053.

Overholt EM, Rubel EW, Hyson RL (1992) A circuit for coding interaural time differences in the chick brainstem. J Neurosci 12:1698-1708.

Parks TN, Rubel EW (1975) Organization of projections from n. magnocellularis to n. laminaris. J Comp Neurol 164:435-448.

Reyes AD, Hyson RL, Rubel EW (1991) Electrophysiological properties of neurons in the chick nuclei magnocellularis and laminaris. Soc Neurosci Abstr 17:446.

Reyes AD, Rubel EW, Spain WJ (1994) Membrane properties underlying the firing of neurons in the avian cochlear nucleus. J Neurosci 14:5352-5364.

Robinson HPC, Kawai N (1993) Injection of digitally synthesized synaptic conductance transients to measure the integrative properties of neurons. J Neurosci Methods 49:157-165.

Rothman JS, Young ED, Manis PB (1993) Convergence of auditory nerve fibers onto bushy cells in the ventral cochlear nucleus: implications of a computational model. J Neurophysiol 70:2562-2583.

Rubel EW, Parks TN (1975) Organization and development of brain stem auditory nuclei of the chicken: lonolopic organization of Il. magnocellularis and $n$. laminaris. J Comp Neurol 164:411-434.

Rubel EW, Parks TN (1988) The developing auditory system. In: Auditory function (Edelman GM, Gall WE, Cowan WM, eds), pp 3-y2. New York: Wiley.

Sharp AA, O'Neil MB, Abbott LF (1993a) The dynamic clamp: artificial conductances in biological neurons. Trends Neurosci 16:389-394.

Sharp AA, O'Neil MB, Abbott LF, Marder E (1993b) Dynamic clamp: computer-generated conductances in real neurons. J Neurophysiol 69:992-995.
Smith DJ, Rubel EW (1979) Organization and development of brain stem auditory nuclei of the chicken: dendritic gradients in nucleus laminaris. J Comp Neurol 286:213-239.

Smith PH (1995) Structural and functional differences distinguish principal from nonprincipal cells in the guinea pig MSO slice. J Neurophysiol 73:1653-1667.

Smith ZDJ (1981) Organization and development of brain stem auditory nuclei in the chicken: dendritic development in $\mathrm{n}$. laminaris. $\mathrm{J}$ Comp Neurol 186:213-240.

Stuart GJ, Sakmann B (1994) Active propagation of somatic action potentials into neocortical pyramidal cell dendrites. Nature 367:69-72.

von Bartheld CS, Code RA, Rubel EW (1989) GABAergic neurons in brainstem auditory nuclei of the chick: distribution, morphology, and connectivity. J Comp Neurol 287:470-483.

Warchol ME, Dallos P (1990) Neural coding in the chick cochlear nucleus. J Comp Physiol 166:721-734.

Wu SH, Kelly JB (1991) Physiological properties of neurons in the mouse superior olive: membrane characteristics and postsynaptic responses studied in vitro. J Neurophysiol 65:230-246.

Wu SH, Oertel D (1984) Intracellular injection with horseradish peroxidase of physiologically characterized stellate and bushy cells in slices of mouse anteroventral cochlear nucleus. J Neurosci 4:1577-1588.

Yin TC, Chan CK (1990) Interaural time sensitivity in medial superior olive of cat. J Neurophysiol 64:465-489.

Young SR, Rubel EW (1983) Frequency-specific projections of individual neurons in chick brainstem auditory nuclei. J Neurosci 3:1373-1378.

Young SK, Kubel EW (1986) Embryogenesis of arborization pattern and topography of individual axons in nucleus laminaris of the chicken brain stem. J Comp Neurol 254:425-459.

Zhang S, Trussell LO (1994) A characterization of excitatory postsynaptic potentials in the avian nucleus magnocellularis. 72:705-718.

7hou N, Parks TN (1991) Pharmacology of excitatory amino acid neurotransmission in nucleus laminaris of the chick. Hear Res 52:195-200. 